\title{
Novel Thunderstorm Alert System (NOTHAS)
}

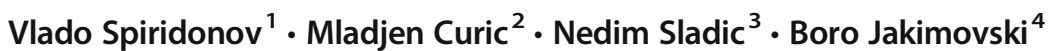

Received: 22 March 2020 / Revised: 22 May 2020 / Accepted: 9 June 2020 / Published online: 6 July 2020

(C) The Author(s) 2020

\begin{abstract}
A "Novel Thunderstorm Alert System" (NOTHAS) has been developed and extensively tested for forecast and warnings of midlatitude and tropical convective events. The design of the system showed some potential advantages compared to earlier alert systems, mainly in reducing uncertainties in predictions by taking the given maximum hourly local-scale signal. It represents a dynamic tool which allows the use of the probability concept of multivariate distribution and integrating it into general function by taking all convective parameters. It utilizes the latest developed microphysical parameterization scheme using a scale and aerosol awareness convective scheme and the sharpest criteria for mid-latitude storms. NOTHAS shows consistency and some kind of flexibility in post-processing applications, regardless of different parameterizations used in the ensemble or deterministic forecasts. The scientific verification shows a high level of accuracy in all significant scores which indicates that severe weather outlooks produced by NOTHAS for several hours ahead are in good alignment with observed thunderstorm activity. This novel tool shows a good performance which has sufficient merit for further additional testing and system evaluation of different severe mid-latitude and tropical storms, tropical cyclones and other severe weather cases across regions.
\end{abstract}

Keywords Severe convective weather · Forecast guidance - Weibull distribution - Thunderstorm categorization level · Verification · Alert system

\section{Introduction}

Severe weather produced by storms represents the most complex and violent type of all adverse weather phenomena. It is usually associated with producing local excessive precipitation and flash-floods, gusty winds, large hail and even tornadoes (e.g. Browning 1962, 1964). The main triggering factors for their occurrence are the presence of substantial wind shearlow-level veering (e.g. Weisman and Rotuno 2000; Weisman and Klemp 1982), large convective available potential energy (CAPE) and lifted index (LI) (see Doswell III et al. 1996). In

Responsible Editor: Eun-Soon Im.

Vlado Spiridonov

vlado.spiridonov@unive.ac.at; vspiridonov@meteo.gov.mk

1 Institute of Meteorology and Geophysics, University of Vienna, Vienna, Austria

2 Institute of Meteorology, University of Belgrade, Belgrade, Serbia

3 International University of Sarajevo, Sarajevo, Bosnia and Herzegovina

4 Faculty of Computer Science and Engineering, "Ss. Cyril and Methodius" University-Skopje, Skopje, Macedonia addition to these, the storm helicity in the layer between 0 and $3000 \mathrm{~m}$, differential heating and the local forcing environment are also important factors for initiation of severe convection and supercells. Doswell III and Schultz (2006) discussed the use of diagnostic variables in severe storm forecasting and their limitations, as well as the effective forecast parameters in designing some new variables for making weather forecasts. Among different supercell storm types, the high precipitation (HP) supercell is responsible for heavy rainfall which is characterized by formation of quasi-steady deep rotating updrafts-mesocyclone, having a longer life cycle and severity. The important aspect is the evolution of storms and some important processes, such as splitting or merging, which lead to convection intensification and occurrence of heavy rainfall and hailfall (e.g. Ćurić et al. 2009; Spiridonov et al. 2010; Ćurić and Janc 2012). Xue et al. (2003, 2008) introduced the innovative aspects in severe weather prediction, including use of convection-allowing model (CAM) ensembles with advanced data assimilation, generation of severe weather outlooks that are valid at periods shorter than those issued operationally, use of CAM to issue the outlooks beyond day 1 period, increased interaction through software, allowing participants to create individual severe weather outlooks and to test newly developed storm attribute-based diagnostics for 
tornado predictions and hail size. Weisman et al. (2008) introduced one possible approach for severe thunderstorm forecast guidance based on ensemble WRF-ARW model forecast and suitable algorithm for automated quantitative assessment of severe thunderstorms and other local-scale hazards over the South-eastern European domain. Stensrud et al. (2009) discuss the warn-on forecast system working on the probabilistic convective scale ensemble analysis and forecasting system, that assimilates in-storm observations into a high-resolution convection-resolving model ensemble. Schultz et al. (2011) examined the in-cloud (IC) and cloud to ground (CG) lightning trends for thunderstorms, in order to demonstrate lightning potential in a specific nowcasting and satellite applications. Thunderstorms forecast and alert are one of the most problematic issues in numerical weather prediction, due to their small scale spatial and temporal resolution (Warner 2011). In that view, an attempt has been made by Spiridonov and Curic (2015) to utilize a cloud-resolving model as forecast guidance for severe weather warning through the definition of flooding indices and potential risk mapping. Recently, comprehensive research has been carried out at the National Severe Storm Laboratory NSSL (see Xue et al. 2008) that aimed to improve the lead time and accuracy of severe weather warnings and forecasts for safety reasons, protection of human life and property damages. For example, Hart and Cohen (2016) developed and tested The Statistical Severe Convective Risk Assessment Model (SSCRAM) to evaluate severe thunderstorm nowcast probabilities over the United States based on hourly mesoscale model output data. More recently, many studies (Clark 2012; Thompson et al. 2012; Gallo et al. 2016; Gallo and coauthors 2017; Gallo et al. 2019) demonstrated a summary diagram which shows the visualization and comparison of convection-allowing model performance across multiple metrics and fields. Severe convective weather phenomena cause significant environmental impacts that are not explicitly resolved by the present weather forecast models. This is due to the uncertainties originated from the lack of explicit resolution and nonlinear-wave nature of different scale atmospheric processes. One of the ways to minimize existing uncertainty is to use the probability forecast based on the cumulative multivariate function (CMF) as the best estimate of a severe weather event occurring within the model grid. This allows reducing in some way the uncertainties in the forecasts, when used as an element in the severe weather alert decision process. It is achieved by including and consulting several key convective parameters with a defined threshold values that significantly affect the initiation and development of severe thunderstorms. Estimating the uncertainty could be very beneficial for severe weather risk assessment, as each individual member (physical and environmental) gives contribution to the overall qualitative and quantitative assessment of threat, along with timing and spatial distribution of the highest-risk area. Therefore, the main motivation behind this research is to develop and test a well-suited algorithm, designed as an integral part of the weather forecast system, serving as the interface between the forecast model and thunderstorm alert outputs.

This paper reports on the results from testing the effectiveness of the Novel Thunderstorm Alert System (NOTHAS). First, the design of the system is explained.. Next, the details about the model forecast guidance and storm alert algorithm are described, followed by a discussion of the results and scientific verification of the system performance with comparison against observations. Finally, the key findings of the study are presented and suggestions for further work required for system improvement and operation are outlined.

\subsection{Design of Novel Thunderstorm Alert System (NOTHAS)}

\subsection{Overview of Current Alert Systems}

The European continent often experiences severe weather events and thunderstorms as a major hazardous weather that causes significant damages to different sectors, infrastructure, crops, economy, and in some extreme cases endangers people's lives. The National Meteorological and Hydrological Services (NMHSs) established and organized their own centres, responsible for forecast and warning of severe weather in collaboration with their authorities. However, under the initiative of the European Weather Services Network (EUMETNET) and in collaboration with the World Meteorological Organization (WMO), an integral official platform has been established, so-called EU MeteoAlert, with the participation of many (NMHS's of member countries) uniform web-based services about information on severe weather conditions. This information is presented consistently, in order to ensure coherent interpretation of warnings, with the general view of potential severe weather across Europe. The information is presented as awareness types (e.g. rain, flood, wind, thunderstorms, heat waves) and shaded colour patterns. Which denote awareness levels (e.g. red-very dangerous weather, orange-dangerous and yellow-potentially dangerous weather). After the development of European Severe Weather Database (ESWD), the European Severe Storms Laboratory (ESSL) has been established in 2006 (see Dotzek et al. 2009). The main mission of ESSL is to study severe convective storms, tornados and heavy rain events across Europe with the collaboration of ESWD. In addition, the European Storm Forecast Experiment (ESTOFEX) on convective weather outlooks, established in 2002, represents a platform for the exchange of meteorological knowledge related to severe convective storm forecasts and warnings across Europe (e.g. Tuschy n.d.; Haklander and van Delden 2003; Dahl et al. 2011a, $2011 \mathrm{~b}$;). It is designed using an extended set of observational, model output data, convective instability parameters based on 


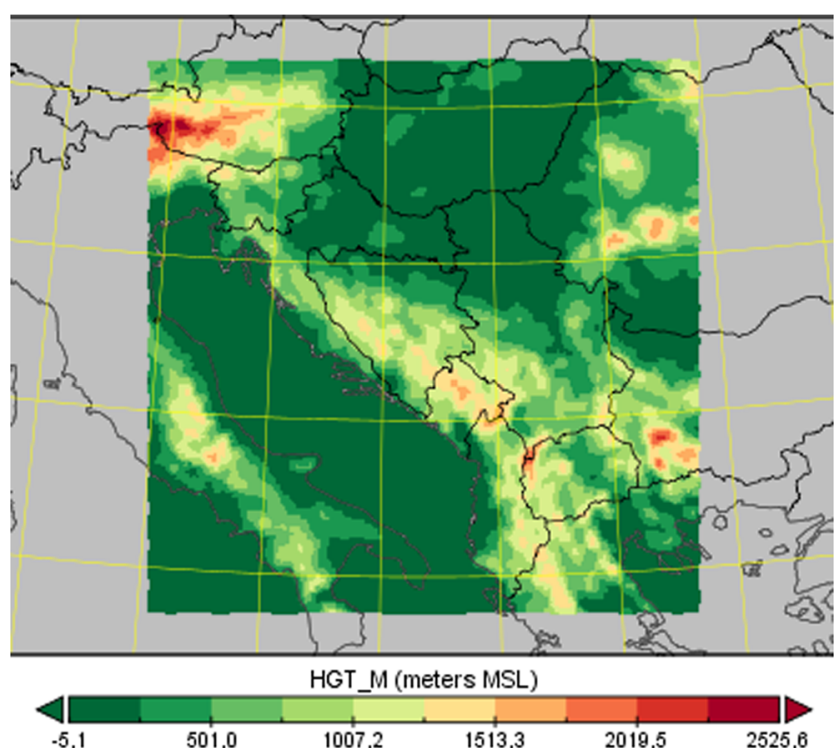

Fig. 1 Model integration domain with landscape for Southeast Europe

the ingredients proposed by Doswell III and Schultz (2006). A daily issued report (valid for $24 \mathrm{~h}$ ) encompasses weather synopsis, severe weather map with probability of occurrence and category levels (from 1 to 3 ) where level 3 means extreme severe storms with the probability of $15 \%$. There are many centres with sophisticated methods and tools for forecast, tracking and warning for severe storms, such as the Storm Prediction Center (SPC) that operates by NOAA National Weather Service. The centre provides convective outlooks in a wide date range up to 8 days ahead with different categorical risk levels and percentage probabilities of severe thunderstorm occurrence within 25 miles of any point. More details about the method and severe weather parameters could be found in other research studies (see for instance, Doswell III and Rasmussen 1994; Weisman 1996; Weisman and Klemp 1982; Blanchard 1998; Thompson et al. 2003; Davies-Jones 1984).

\subsection{A Novel Thunderstorm Alert System (NOTHAS)}

A Novel Thunderstorm Alert System (NOTHAS) is an advanced forecast and diagnostic system for early assessment of storm intensity and alert category of severe thunderstorm threats across the selected area. It consists of WRF model
Table 1 WRF-ARW model configuration

\begin{tabular}{ll}
\hline Horizontal grid & $5,0 \mathrm{~km}$ \\
\hline Vertical levels & 34 \\
Time step & $30 \mathrm{~s}$. \\
PBL Scheme & Planetary Boundary Layer (PBL) \\
& Physics-YSU Scheme Hong et al. (2006) \\
& A nonlocal PBL Scheme with scale dependent \\
& added to WRF (Shin and Hong 2011) \\
Cumulus convection parametrization & NCEP GFS Cumulus Convection Scheme with \\
& scale and aerosol awareness (Shin and Hong, \\
& 2015; Han et al. 2017) \\
Dudhia Shortwave Scheme & Dudhia Scheme: Simple downward integration \\
& allowing for efficient cloud and clear-sky \\
absorption and scattering. Dudhia, (1989) & Mlawer et al. (1997) \\
RRTM Longwave Scheme & Thompson Graupel Scheme: a scheme with six \\
Microphysics & classes of moisture species plus number \\
& concentration for ice as prognostic variables. \\
Thompson et al. (2008). & Thompson microphysics scheme with aerosol \\
climatology (Thompson and Eidhammer 2014) & Tewari et al. (2004)
\end{tabular}

Unified Noah Land Surface Model

Unified, NCEP/NCAR/AFWA Scheme

with soil temperature and moisture in four layers,

fractional snow cover and frozen soil physics

Surface-layer option

Janjic, (1994)

Monin-Obukhov (Janjic Eta) Similarity scheme: based on similarity theory with viscous sublayers both over solid surfaces and water points Initial and Boundary Conditions

\section{(}

NCEP GFS global model $0.25^{\circ}$

GFS initial data - a boundary conditions at each $3 \mathrm{~h}$ 
forecasts outputs and a diagnostic algorithm based on Weibull distribution, including a set of instability parameters with threshold criteria. The system utilizes the hourly output data from a routine ensemble or deterministic forecasts obtained from the Advanced Research WRF (ARW - Skamarock et al. 2008; 2011) model, to produce daily, 24 to $72 \mathrm{~h}, 5 \mathrm{~km}$ forecasts over the South-eastern Europe (SEE) (see Fig. 1). The configuration of the model suite is summarized in Table 1. The WRF system has been enhanced to supplement standard WRF output fields. Each field represents the maximum that occurred in the previous hour (i.e. maximum at each of the model's time steps in the past hour). This strategy permits the capture of storm-scale features in the model that have short lifetimes and might be missed using hourly values. Additionally, this approach allows for this tool to be used in combination with current radar and lightning observations or other tools for storms as well as other local scale hazards tracking algorithms.

\subsection{WRF Model Configuration}

The WRF modelling system is based on the Advanced Research WRF-ARW core developed by NCAR (Skamarock et al. 2005; 2008). As an advantage, the forecast of severe convection model uses cumulus convection scheme with scale and aerosol awareness developed by Han et al. (2017), the new nonlocal PBL scheme with scale dependent added to WRF (Shin and Hong 2011) ${ }^{1}$ and the Thompson microphysics scheme with aerosol climatology (Thompson and Eidhammer 2014). More details about the model configuration are shown in Table 1. In our forecasting system, both model versions are executed with a $5 \mathrm{~km}$ grid-length, with a domain covering a mesoscale region, and driven using initial conditions and Lateral Boundary Conditions (LBCs) from the NCEP GFS global model. The developed system has a flexible design which allows WRF configuration of one-way interactive nested domain or single model domain. A wellsuited algorithm has been designed as an integral part of the system, serving as the interface between the models. The model can be run in a single forecast domain or nested domain covering a nation-scale region and driven using initial conditions and Lateral Boundary Conditions (LBCs) from the NCEP GFS global model.

\subsection{Thunderstorm Diagnostic Approach}

The second component of the system represents a storm diagnostic algorithm (tool) based on the Weibull probability density function and convective parameters. The Weibull distribution

\footnotetext{
${ }^{1}$ Personnel communication with Prof. Dr. Song-You Hong from Yonsei University, regarding to the convection scheme with scale and aerosol awareness
}

function allows flexible estimation of the uncertainties of occurrence of severe thunderstorms due to the non-linear nature of the atmospheric processes, scalability, and lack of the explicit grid resolution for explicit treatment of small scale processes, different model configurations, initialization and parameterizations. Thus, to underline this uncertainty to a certain degree the following Weibull distribution is used as a multivariate cumulative distribution function (MCDF):

$\operatorname{MCDF}\left(X_{i=1, N}\right)=\sum_{i=1}^{N} \operatorname{CDF}\left(X_{i=1, N}\right)=\sum_{i=1}^{N}\left[1-e^{-\left(\frac{x_{i}-X_{0 i}}{Y_{i}}\right) Z_{i}}\right]$

where CDF represents a cumulative distribution function which estimates the probability of a given variable to be less or equal to its threshold value. $X_{i}$ in Eq. 1 is threshold value for the appropriate variable for $\mathrm{i}=1, \mathrm{~N} ; X_{0}$ is constant that determines the start of the distribution on the $x$-axis, $Z_{i}$ defines where the bulk of the distribution lies, and $Y_{i}$ varies from grid point to grid point within the model run and $\mathrm{X}$ gives the pattern of the distribution. MCDF can be written in the developed form as:

$$
\begin{aligned}
& \operatorname{MCDF}\left(X_{i=1,10}\right)=\left[1-e^{-\left(\frac{x_{1}-X_{01}}{Y_{1}}\right) Z_{1}}\right]+\left[1-e^{-\left(\frac{X_{2}-X_{02}}{Y_{2}}\right) Z_{2}}\right] \\
& +\left[1-\mathrm{e}^{-\left(\frac{\mathrm{x}_{3}-\mathrm{x}_{03}}{\mathrm{Y}_{3}}\right) \mathrm{Z}_{3}}\right]+\left[1-\mathrm{e}^{-\left(\frac{\mathrm{x}_{4}-\mathrm{X}_{04}}{\mathrm{Y}_{4}}\right) \mathrm{Z}_{4}}\right] \\
& +\left[1-\mathrm{e}^{-\left(\frac{\mathrm{x}_{5}-\mathrm{x}_{05}}{\mathrm{Y}_{5}}\right) \mathrm{Z}_{5}}\right]+\left[1-\mathrm{e}^{-\left(\frac{\mathrm{x}_{6}-\mathrm{x}_{06}}{\mathrm{Y}_{6}}\right) \mathrm{Z}_{6}}\right] \\
& +\left[1-\mathrm{e}^{-\left(\frac{\mathrm{X}_{7}-\mathrm{X}_{07}}{\mathrm{Y}_{7}}\right) \mathrm{Z}_{7}}\right]+\left[1-\mathrm{e}^{-\left(\frac{\mathrm{x}_{8}-\mathrm{X}_{08}}{\mathrm{Y}_{8}}\right) \mathrm{Z}_{8}}\right] \\
& +\left[1-\mathrm{e}^{-\left(\frac{x_{9}-x_{09}}{Y_{9}}\right) Z_{9}}\right]+\left[1-\mathrm{e}^{-\left(\frac{x_{10}-x_{10}}{Y_{10}}\right) Z_{10}}\right]
\end{aligned}
$$

This new approach allows the use of multiple key output variables, in which a probability can be determined for any threshold $X_{i}$ in Eqn. (2). More specifically, diagnostic algorithm provides one output variable to describe a given specific uncertainty, and their sum to determine the overall (integral) uncertainty for occurrence of the severe convective weather within one grid box. The method enables flexibility in our post-processing algorithm as the result of relatively simple diagnosis of uncertainty which can be determined for any threshold value $X_{i=1, N}$. NOTHAS diagnostic package is comprised with a set of combined physical and potential convective instability parameters expressed in terms of the multivariate cumulative distribution function as a diagnostic tool with defined threshold values for given severe convective weather indices and physical parameters listed in Table 2. A more detailed description of all convective instability terms and their relations are given in the Appendix. The Weibull curve for the precipitation (as the most significant parameter) 
closely follows a Gaussian distribution. Thus for the coefficient $Z_{i}$ which determines where the bulk distribution lies, $Z_{10}=3.6$, while for all other variables $Z_{i}=1$ (see the last column in Table 2). Each listed parameter participates with a different weighted factor into a multivariate cumulative distribution function. The precipitation is considered a substantial parameter in the assessment of the storm intensity and flooding potential. Thus it accounts for $100 \%$, while other given potential (convective) instability parameters account for about $55.5 \%$ in overall MCDF contribution. The forecast probability specifies the level of the overall severe weather threat via numbers, for example, "1", with descriptive labelling "MARGINAL" which means "marginal thunderstorms are expected", and shaded with "green" colour in the legend and also on an output visualization map. Other specified levels from (2-5) denote "SLIGHT"; "ENHANCED"; "SEVERE" and "EXTREME" level of the overall severe weather threat, respectively. More specifically, number "2" indicates an isolated thunderstorm possibility; " 3 " indicates numerous severe storms; "4" indicates widespread very severe well-organized thunderstorms, and " 5 " indicates widespread extremely severe or supercell storms (see Fig. 2). The probabilistic forecast directly expresses the best estimate of a severe weather event occurring within $25 \mathrm{~km}$ of a middle grid point using a bilinear interpolation. The advanced diagnostic tool utilizes WRF forecast guidance on output times. Hence, The Novel Thunderstorm Alert System (NOTHAS) is a flexible tool as it provides convective weather outlooks on an hourly basis, which are derived from both deterministic and ensemble forecasts with suite diagnostic algorithm. The ensemble approach in our case implies using a set of initial conditions by scaling of the input or created by perturbing a single "base" model configuration of physics and dynamics options. The other relatively simple ensemble method is based on using a fifteen (15) members, mostly in terms of WRF model of physical parameterizations (radiation, microphysics, atmospheric boundary layer ABL schemes, turbulence closure, convective parameterization) and dynamics options (diffusion, advection), as well as lateral boundary conditions (e.g. Stensrud et al. 2000; Eckel and Mass 2005). In the case where the

Table 2 Convective instability and Weibull parameters

\begin{tabular}{|c|c|c|c|}
\hline $\begin{array}{l}\text { Potential (convective) instability and } \\
\text { physical parameters }\end{array}$ & $\begin{array}{l}\text { Threshold values } \\
\text { for a mid-latitude convec- } \\
\text { tion }\end{array}$ & Instability description & $\begin{array}{l}\text { The Weibull } \\
\text { parameters } \\
\text { for probability }\end{array}$ \\
\hline $\begin{array}{l}\text { Total Totals Index }(\mathrm{TT}) \\
\mathrm{TT}=\mathrm{T}(850 \mathrm{mb})-\mathrm{T}(500 \mathrm{mb})+\mathrm{Td}(850 \mathrm{mb})-\mathrm{T}(500 \mathrm{mb})\end{array}$ & $\mathrm{TT}=55-60\left({ }^{\circ} \mathrm{C}\right)$ & $\begin{array}{l}\text { Severe thunderstorms } \\
\quad \text { most likely }\end{array}$ & $\begin{array}{l}Z_{1}=1.0 \\
Y_{1}=0.55 x T T \\
X_{01}=T T-Y_{1}\end{array}$ \\
\hline $\begin{array}{l}\text { K-Index as measure of thunderstorm potential } \\
\mathrm{K}=\mathrm{T}(850 \mathrm{mb})+\mathrm{Td}(850 \mathrm{mb})-\mathrm{T}(500 \mathrm{mb})-\mathrm{DD}(700 \mathrm{mb})\end{array}$ & $\mathrm{K}=40$ & $\begin{array}{l}\text { Best potential for } \\
\text { thunderstorms } \\
\text { with excessive rainfall }\end{array}$ & $\begin{array}{l}Z_{1}=1.0 \\
Y_{1}=0.55 x K \\
X_{01}=K-Y_{1}\end{array}$ \\
\hline $\begin{array}{l}\text { Severe Weather Threat Index }(\text { SWEAT }) \\
\text { SWEAT }=12[\mathrm{Td}(850 \mathrm{mb})]+20(\mathrm{TT}-49)+2(\mathrm{f} 8)+\mathrm{f} 5+125(\mathrm{~S}+0.2)\end{array}$ & SWEAT $>350$ & $\begin{array}{l}\text { Potential for severe } \\
\text { thunderstorms }\end{array}$ & $\begin{array}{l}Z_{2}=1.0 \\
Y_{2}=0.55 x S W E A T \\
X_{02}=S W E A T-Y_{2}\end{array}$ \\
\hline $\begin{array}{l}\text { Convective Available Potential Energy (CAPE) } \\
C A P E=\int_{p_{f}}^{p_{n}} R_{d}\left(T_{v p}-T_{v e}\right) d \ln p\end{array}$ & CAPE > $3500(\mathrm{~J} / \mathrm{kg})$ & Extremely unstable & $\begin{array}{l}Z_{3}=1.0 \\
Y_{3}=0.55 x S W E A T \\
X_{03}=S W E A T-Y_{3}\end{array}$ \\
\hline $\begin{array}{l}\text { Lifted Index }(\mathrm{LI}) \\
L I=T\left(500 m b_{e n v}\right)-T\left(500 m b_{\text {parcel }}\right)\end{array}$ & $\mathrm{LI}<-9$ & Extremely unstable & $\begin{array}{l}Z_{4}=1.0 \\
Y_{4}=0.55 x L I \\
X_{04}=L I-Y_{4}\end{array}$ \\
\hline $\begin{array}{l}\text { Bulk Richardson's Number (BRN) } \\
B R N=\frac{\left(g / T_{v}\right) \Delta \theta_{v} \Delta z}{\left(\Delta u^{2}\right)+\left(\Delta v^{2}\right)}\end{array}$ & $\mathrm{BRN}=10-45$ & Supercell development & $\begin{array}{l}Z_{5}=1.0 \\
Y_{5}=0.55 x B R N \\
X_{05}=B R N-Y_{5}\end{array}$ \\
\hline $\begin{array}{l}\text { Storm Relative Helicity (SRH) } \\
S R H=-\int_{0}^{h}\left[(\vec{V}-\vec{C}) \cdot \vec{k} x\left(\frac{\partial V}{\partial z}\right)\right] d z\end{array}$ & $\mathrm{SRH}>150 \mathrm{~m}^{2} / \mathrm{s}^{2}$ & $\begin{array}{l}\text { The approximate threshold } \\
\text { for supercell development }\end{array}$ & $\begin{array}{l}Z_{7}=1.0 \\
Y_{7}=0.55 x S R H \\
X_{07}=S R H-Y_{7}\end{array}$ \\
\hline $\begin{array}{l}\text { Max Radar Reflectivity (dBZ) } \\
\text { (REFD) }\end{array}$ & $\mathrm{REFD}=60$ & $\begin{array}{l}\text { Very severe thunderstorms } \\
\quad \text { possible }\end{array}$ & $\begin{array}{l}Z_{8}=1.0 \\
Y_{8}=0.55 x R E F D \\
X_{08}=R E F D-Y_{8}\end{array}$ \\
\hline $\begin{array}{l}\text { Brightness temperature } \\
\left({ }^{\circ} \mathrm{C}\right)(\mathrm{BRTH})\end{array}$ & $\mathrm{BRTH}<-60{ }^{\circ} \mathrm{C}$ & $\begin{array}{l}\text { Deep convection with } \\
\text { overshooting tops }\end{array}$ & $\begin{array}{l}Z_{9}=1.0 \\
Y_{9}=0.55 x B R T H \\
X_{9}=B R T H-Y_{9}\end{array}$ \\
\hline $\begin{array}{l}\text { Total Accumulation of Precipitation from } \\
\text { the convection and microphysics scheme } \\
(\mathrm{mm}) \text { RAINT = (RAINS+RAINNC) }\end{array}$ & $\begin{array}{l}\text { RAINT }=30 \mathrm{~mm} \\
\text { tot. Acc. (in } 1 \mathrm{~h} \text { ) }\end{array}$ & $\begin{array}{l}\text { Severe thunderstorms and } \\
\text { flash flooding }\end{array}$ & $\begin{array}{l}Z_{10}=3.6 \\
Y_{10}=0.4 x R A I N T \\
X_{10}=R A I N T-Y_{10}\end{array}$ \\
\hline
\end{tabular}




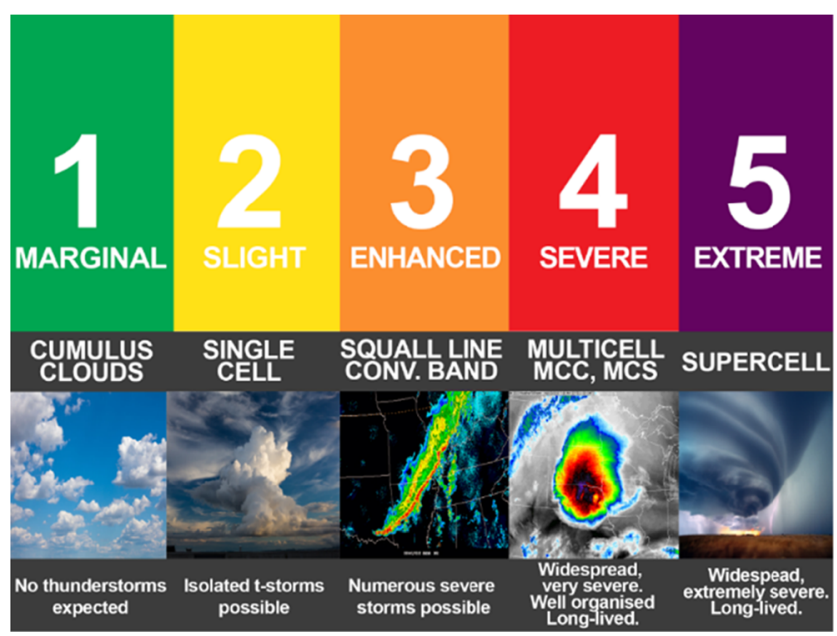

Fig. 2 NOTHAS storm category and alert levels

ensemble approach is not always suitable for real-time running (especially when the available computing resources are limited), the flexibility of the system with a new diagnostic algorithm allows the use of a deterministic method given that the diagnostic package incorporates a set of key convective parameters as important elements for triggering convection. In general, the system provides a general overview of the weather patterns, emphasizing features that will influence the severe and general thunderstorm threats as useful information for severe weather forecast centres which issue their own official warnings. The graphical outputs on an hourly basis depict non-severe thunderstorm areas and severe thunderstorm threats across the selected model domain, along with a mesoscale discussion and a text narrative displayed 1-3 days ahead. Areas with categorical risk are plotted in standard weather maps with shaded patterns and numbers on an hourly basis.

\section{Results}

\subsection{Observational and Comparative Analysis of the Results}

Novel Thunderstorm Alert System (NOTHAS) was running during the whole 2019 season for domain that covers Southeastern Europe (SEE). The results (on a daily basis) were compared with the total lightning flash rate tendency, provided by Network for Lightning and Thunderstorms in Real-Time (Blitzortung.org). In addition, the system was tested with available meteorological, satellite and radar data to document and verify the performance of the system for detecting and nowcasting the occurrence of severe weather over the selected area. In order to avoid burdening this work with numerous results, we have decided to present only those characteristic severe convective weather cases in 2019 and one historical case that occurred on August 6th, 2016, in Macedonia.
A combined set of observational, modelling and verification data has been provided to evaluate the system skills and its performances in anticipation of severe weather. A brief observational analysis of each selected case is based on the vertical stratification of the atmosphere and thermodynamic parameters derived from upper air soundings. All reported cases are examined according to the $500 \mathrm{hPa}$ geopotential heights and surface pressure analysis. In parallel, we present the results from NOTHAS system and discuss them in light of potential convective instabilities, lightning observational data and severe weather potential during the most intense period of thunderstorms evolution.

\subsection{A Mid-Latitude Deadly Supercell Storm over Skopje, August 6th, 2016}

Atmospheric conditions based on the pressure charts for August 6th, 2016, at 00 UTC and GFS 06Z reanalysis show that there were favourable conditions for the severe storm system development in most parts of the Balkans, including North Macedonia, as there existed a collision between very warm North African and cool continental air mass. The moist, cooler oceanic air mass from the eastern Atlantic penetrated southwards with northerly winds to the Genoa Bay on August 5th, where the cyclogenesis occurred above the warm sea surface. The meeting condition between cooler and warm air resulted in the stationary frontal development across Central Europe due to the equalized air pressure and differences between the warmer and cooler air, and the occluded front in the Genoa Bay, which were the perfect conditions for the significant rainfall as the triple point occurred. This system moved with the typical path south-eastwards during August 6th, with the corresponding developments of couple upper lows along the Adriatic and the Tyrrhenian Sea that brought very warm and moist southerly and south-easterly winds to North Macedonia, causing the temperatures at $850 \mathrm{hPa}$ surface being above average (averaging between 19 and $21{ }^{\circ} \mathrm{C}$ at $12: 00$ UTC), producing temperatures at $2 \mathrm{~m}$ above $30^{\circ} \mathrm{C}$ during the PM hours. A very long frontal zone stretched from the Genoa Bay up to the Euroasia caused frontal instabilities that passed through Croatia, Bosnia and Herzegovina, Montenegro and Kosovo, containing cooler and moist air towards northern North Macedonia. The combination of cooler air with the prior heated surface produced the thermal energy for the warmer air to be lifted upwards, and cooler, moist air to sink down. This resulted in vertical cloud development (Cumulonimbus $(\mathrm{Cb})$ clouds) that produced significant rainfall. The stationary front was pushed eastwards due to strengthening of the Azores High and its ridging towards the northern Balkans. The cooler air from its front side brought cool northeasterly winds, resulting in the change of the stationary front to the cold front. 
Fig. 3 NOTHAS outputs (left panels) compared to the real-time lightning maps provided by Network for Lightning and Thunderstorms in Real Time (right panels) during mid-latitude deadly supercell storm over Skopje, North Macedonia on August 6th, 2016-16:00-19:00 UTC
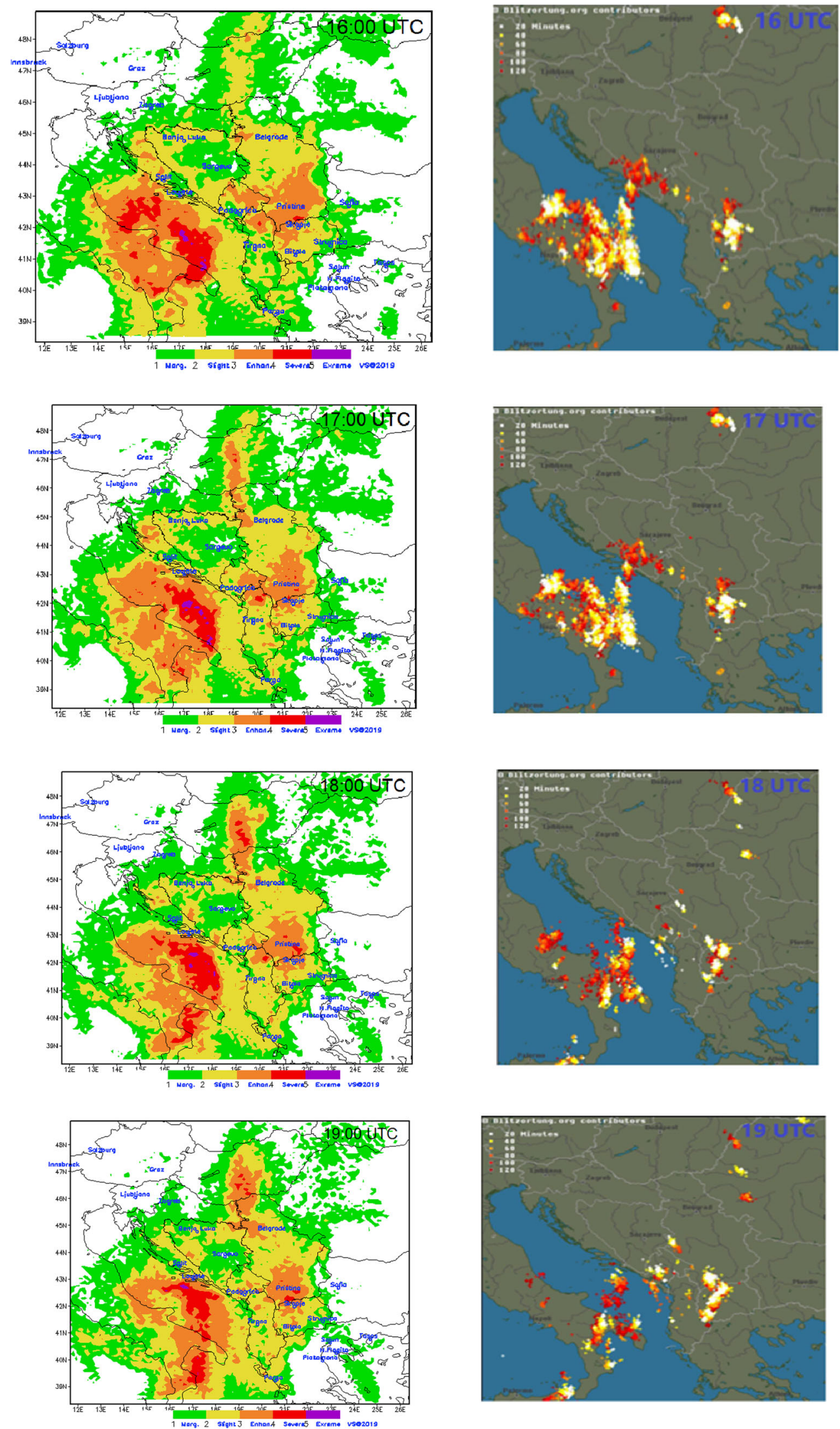
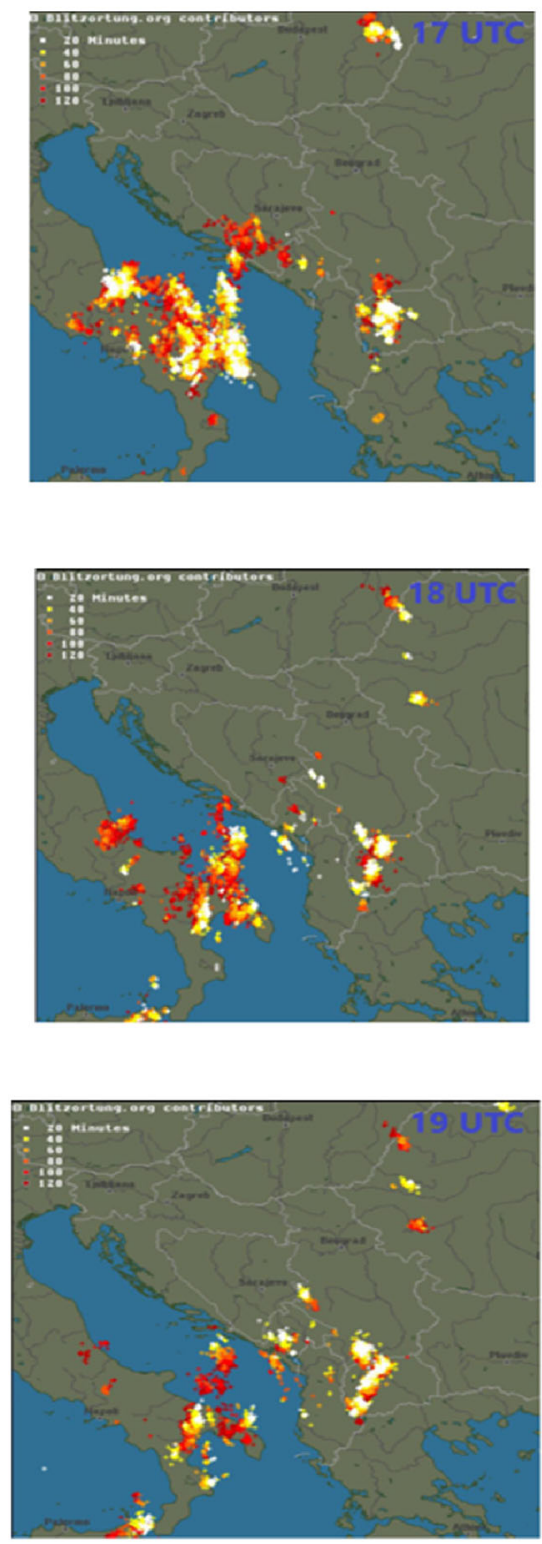
Fig. 4 (a) Meteosat 0 degree Multi-Sensor Precipitation Estimate Eastern Europe (rain rate $\mathrm{mm} / \mathrm{h}$ ), MPEF MPE; (b) Composite radar reflectivity CAPPI (dBZ) at $2 \mathrm{~km}$ height (Source: RHMS); (c) Lightning map over SEE (http://en. blitzortung.org/historical_maps. php) and NOTHAS severe thunderstorm alert issued for August 6th, 2016 18:00 UTC

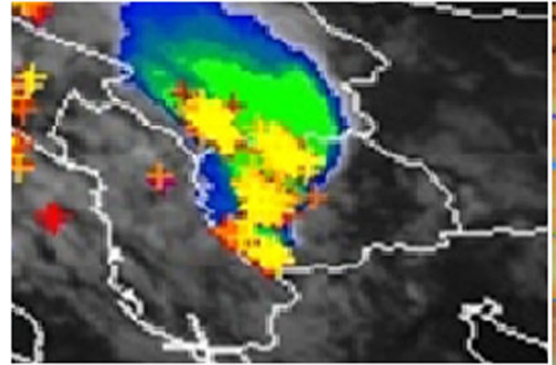

(a)

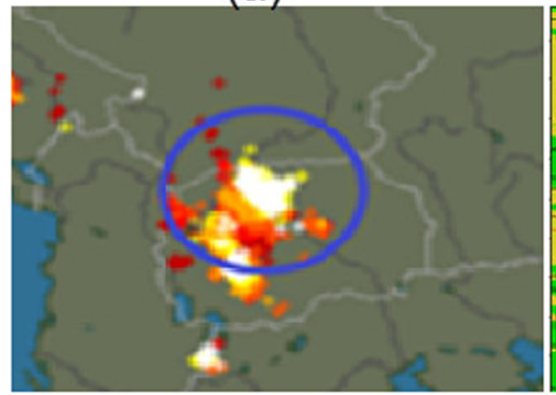

(c)

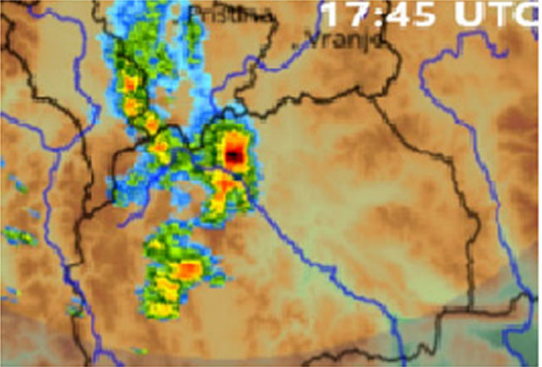

(b)

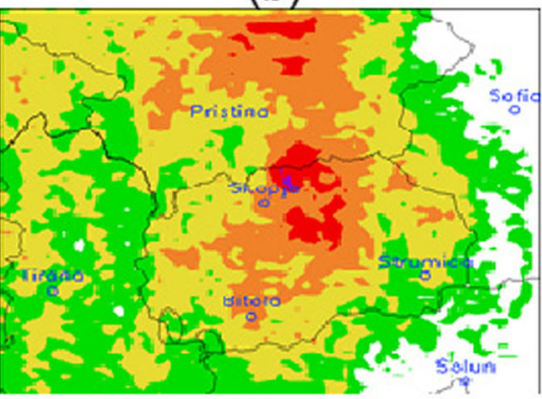

(d)
This novel system showed a high spatiotemporal agreement with real-time lightning data, $24 \mathrm{~h}$ in advance. As it is shown in Fig. 3, a two lightning cores over southwest Adriatic Sea and north-eastern part of North Macedonia are correctly predicted in advance. The time evolution patterns with widespread very severe weather with organized multicellular clusters of storms from 16:00 to 19:00 UTC are fairly well reproduced from NOTHAS, initialized on August 6th, 2016, 00:00 UTC. Indeed, it is surprising that some small-scale convection modes, and local-scale hazards, have been successfully captured by this system. The close similarity between modelled and available satellite, radar and lightning are quite evident looking closer at the areas affected with very severe (red shaded patterns) to extreme convective weather (pink colour). Obviously, lightning patterns in this very particular severe storm case are closely correlated to severe thunderstorm activity over a small domain which covers the Skopje urban area. Hence, an assessment of the relative utility of the respective lightning data types can be potentially considered to be significant guidance for comparison in this specific warning decision support application. NOTHAS has also shown rather excellent agreement in comparison with satellite and radar images, at the most intense stage of supercell storm evolution about 18:00 UTC, accurately detecting a small area with extremely severe weather where heavy convective rainfall is observed.

\subsection{A Mid-Latitude Deadly Supercell Storm over Belgrade, June 23rd, 2019}

Albeit the surface level is shown near average atmospheric pressure over Serbia, an upper low situated above the western
Balkans at $500 \mathrm{hPa}$ level surface in collision with warm $850 \mathrm{hPa}$ level contributed to the unsettled atmosphere over Belgrade area on June 23rd, 2019, resulting in excessive rainfall capable of producing widespread flooding. The $12 \mathrm{Z}$ atmospheric sounding measurements at Belgrade-Košutnjak station showed clear signals of persistently increased unsettledness for many sounding indices, including total-totals (TT), CAPE, K, SWEAT, BRN and lifted index (LI). Southerly to south-westerly (SSW) circulation in the upper troposphere levels prevailed (reaching the height as high as 17,6 km), with cooler and humid air, while warmth was the dominant feature at the surface. Due to the unsettled atmospheric conditions, the moist adiabatic lapse rate (MALR) prevailed, continuously causing the air parcel to lift up. The point at which the air parcel reached the saturation point occurred at nearly $2,24 \mathrm{~km}$ above the ground. The lowest temperature of $-58,5{ }^{\circ} \mathrm{C}$ was measured at $18,6 \mathrm{~km}$ above the ground, while the equilibrium state was reached at roughly $13,4 \mathrm{~km}$, which are the level boundaries for the vertical cloud development.

Figure 5 shows a comparison between the spatial distribution of lightning patterns observed on June 23rd, 2019 from 14:00 to 17:00 UTC, and the areas with categorical risk, obtained with NOTHAS. The model is initialized with initial and boundary conditions data from GFS $0.25^{\circ}$, on June 23rd, 2019, 00:00 UTC. In general, the modelled patterns provided by this novel system fit well with lighting data. The severe thunderstorms are mainly observed across the central portions of the model domain. A slight overestimation of storm intensity is detected in the south-eastern part (over Bulgaria). The similarity between patterns is also evident at 16:00 UTC when extremely severe weather, with convective storms, lightning, 
Fig. 5 Same as Fig. 3 but for a mid-latitude storm over Belgrade, Serbia on June 23rd, 2019 from 14:00-17:00 UTC
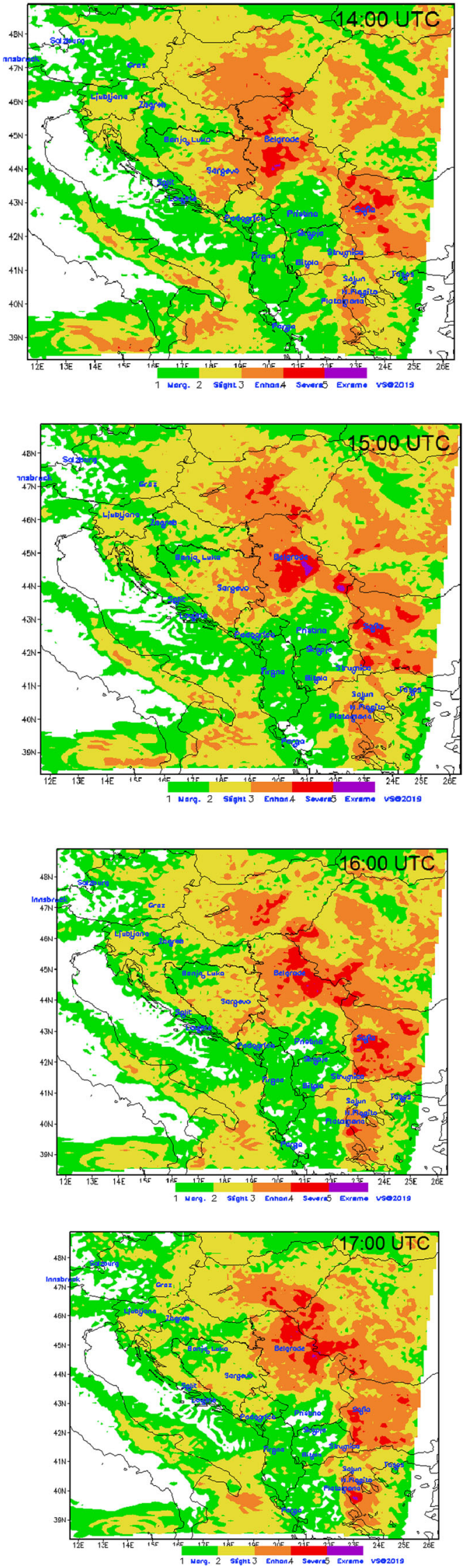
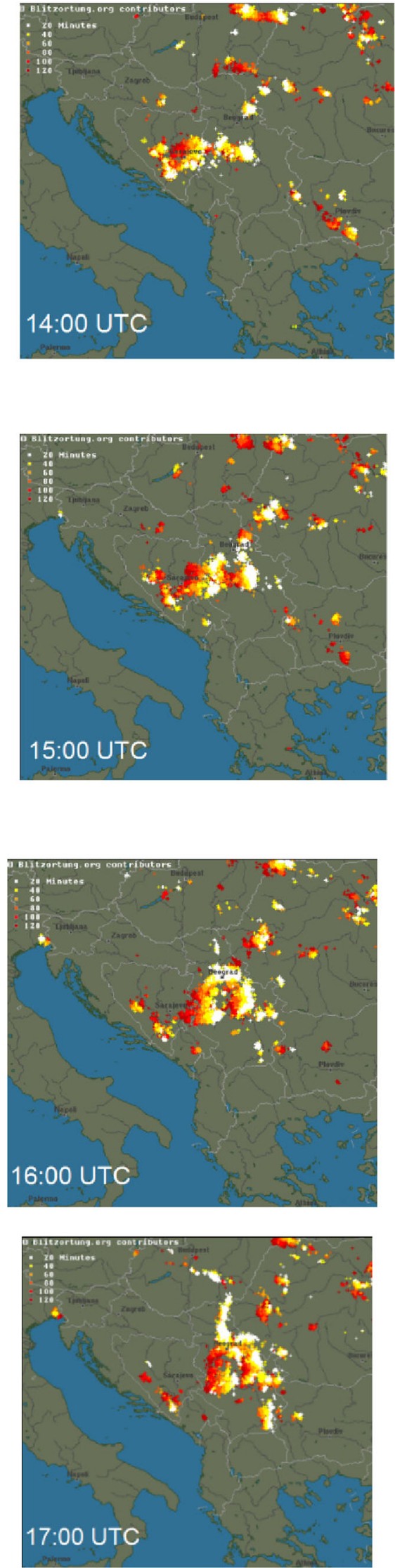

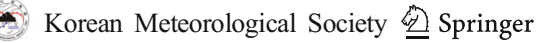


torrential rain and flooding is observed over Belgrade. A pink colour evidenced on NOTHAS category risk map in the vicinity of Belgrade clearly implied about the accuracy of the model in timing and spatial issuing warning of areas with very hazardous weather over Belgrade.

\subsubsection{A Mid-Latitude Supercell Storm over Halkidiki, July 10th, 2019}

After the first significant heatwave of the summer, the stretched cold front pushing from central Europe southeastwards with the combination of a low-pressure system in the Ionian Sea with $1005 \mathrm{hPa}$ in its centre produced a significant storm system that affected northern parts of Aegean Greece on July 10th, 2019. These factors were clearly visible at the surface, while at $500 \mathrm{hPa}$ level a collision between cooler air mass from the northwest and hot from the south existed, pivotal for stronger vertical cloud development as a result of the higher temperature gradient. The low in the Ionian Sea constantly brought very warm and humid air in the south-easterly flow that kept the humidity levels high during afternoon hours. Warm sea surface temperature and higher daily humidity levels in combination with persistently hot North African air mass, both at the surface and at the $850 \mathrm{hPa}$ level, contributed to the higher evaporation levels that are the main link to the excessive rainfall at Thessaloniki region. As the low moved eastwards, it strengthened its centre from 1005 to $1003 \mathrm{hPa}$, reaching Ionian Greece in the evening hours. While cold front was traversing the northern part of Greece, the secondary upper low was formed over the Sporades, contributing to south-eastern flow over the Halkidiki region, bringing bouts of heavy rain.

The $00 \mathrm{Z}$ atmospheric sounding measurements at Thessaloniki station on July 10th showed signals of increased unsettledness for many sounding indices, including totals-totals (TT) and K index, while Severe Weather Treat Index (SWEAT) and lifted index (LI) were lower. Westerly to north-westerly (WNW) circulation in the upper troposphere levels prevailed with cooler air, while warmth and south-easterly flow were dominant features at the surface. Due to the unsettled atmospheric conditions observed, the moist adiabatic lapse rate (MALR) prevailed, continuously causing the air parcel to lift up, which was the case with Belgrade and Skopje. The point at which the air parcel reached the saturation point occurred at nearly $2,8 \mathrm{~km}$ above the ground, while the equilibrium state was reached at roughly $12,2 \mathrm{~km}$, which are the level boundaries for the vertical cloud development. This was a specific case when a large portion of Halkidiki area (northwest Greece) on July 10, 2019 in the evening hours from 18:00 to 21:00 UTC was affected by very severe thunderstorms. Results shown in Fig. 6 indicate that lightning data demonstrate the presence of increased lightning activity over south-eastern parts of the Apennine Peninsula, the Adriatic Sea and Albania prior to the onset of severe weather over Halkidiki, Greece. Squall line form ahead of a cold front was rapidly moving from the northwest towards southeast part producing extremely severe weather in the form of heavy rainfall and strong winds over Halkidiki when six people (mainly tourists) lost their lives. NOTHAS was quite successful as $24 \mathrm{~h}$ in advance it anticipated the time, location and intensity of the occurrence of such severe convective weather over the northern parts of Aegean Greece on July 10th, 2019. The NOTHAS severe weather risk patterns showed an exceptional similarity with areas with increased lightning occurrence. Even more, the NOTHAS was able to capture the categorical risk level "extreme" over Halkidiki with 18 h leading time, which is a quite optimistic result of severe weather alert applications.

\subsubsection{A Mid-Latitude Storm over Sarajevo, June 5th, 2019}

Following a rather wet and cold May, the first days of June kept the prevalence of an upper low situated above Romania, pulling a cooler air mass from the northeast, while on the surface a near-normal pressure was a dominant feature, accompanied with the instability line passing across northern parts of Serbia and a shallow low-pressure system with its centre above central Europe. Such conditions were crucial for stronger convection, due to prevalent wet soil moisture since May and daily high temperatures that allowed air parcel to continuously lift up. Due to moist adiabatic lapse rate (MALR), excessive saturation and cooling have been reached that resulted in strong vertical cloud development, causing excessive rainfall above the valley. According to the National Hydrometeorological Service of Federation of Bosnia and Herzegovina, it was the second greatest rainfall amount ever recorded as $34 \mathrm{~mm}$ had fallen in just $30 \mathrm{~min}$. Such stretched convective band has badly affected the old town Baščaršija, causing flash flooding and significant damage. Due to the fact that atmospheric sounding indices are not available for Sarajevo-Bjelave, a clearer, sharper storm diagnostics cannot be further demonstrated as the cases in Belgrade and Thessaloniki. NOTHAS was also utilized for testing severe weather alerts of several other atmospheric systems associated with stormy weather across different global latitudes. For example, the system was successfully used in evaluation of severe weather associated with the tropical cyclone "Dorian" on September 1st, 2019, and the tropical storm "Pabuk" on January 4th, 2019, two severe thunderstorms that hit Paraguay, Brazil, Thailand, Canada. Nevertheless, our goal is to present the results of several specific situations related to severe convective weather over SEE model domain. 
Fig. 6 Same as Fig. 3 but for a mid-latitude deadly supercell storm over Thessaloniki and Halkidiki, Greece on July 10th, 2019-18:00-21:00 UTC
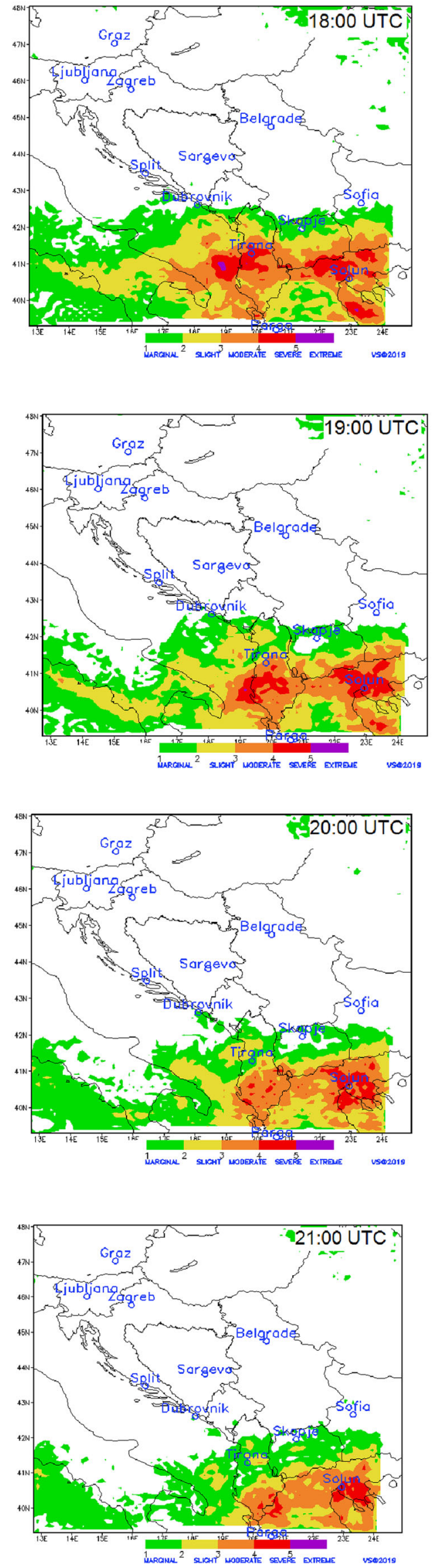
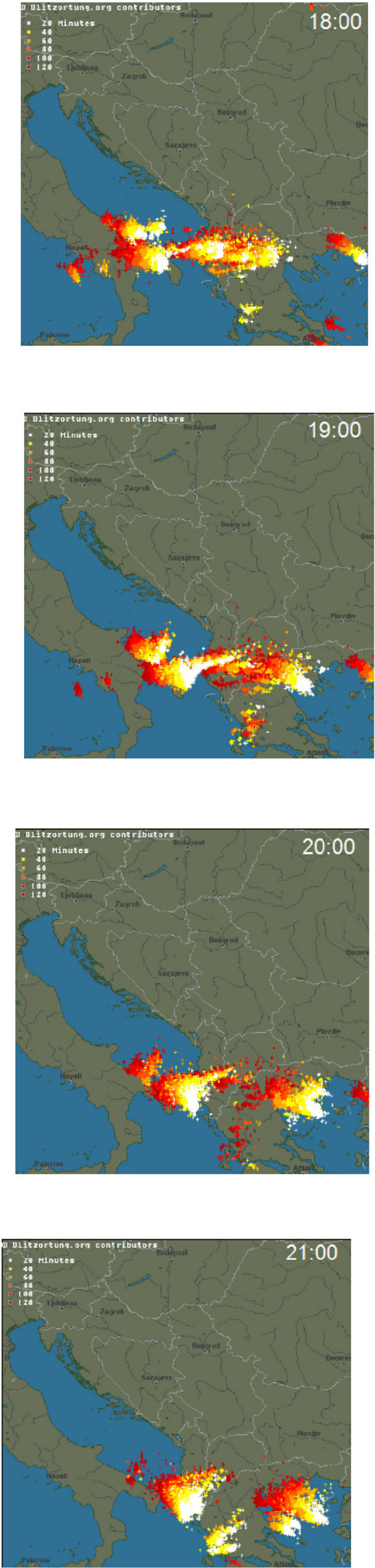

Korean Meteorological Society Springer 
Fig. 7 Same as Fig. 3 but for a mid-latitude single-cell pulse storm over Sarajevo, Bosnia and Herzegovina on June 05th, 2019 13:00-16:00 UTC
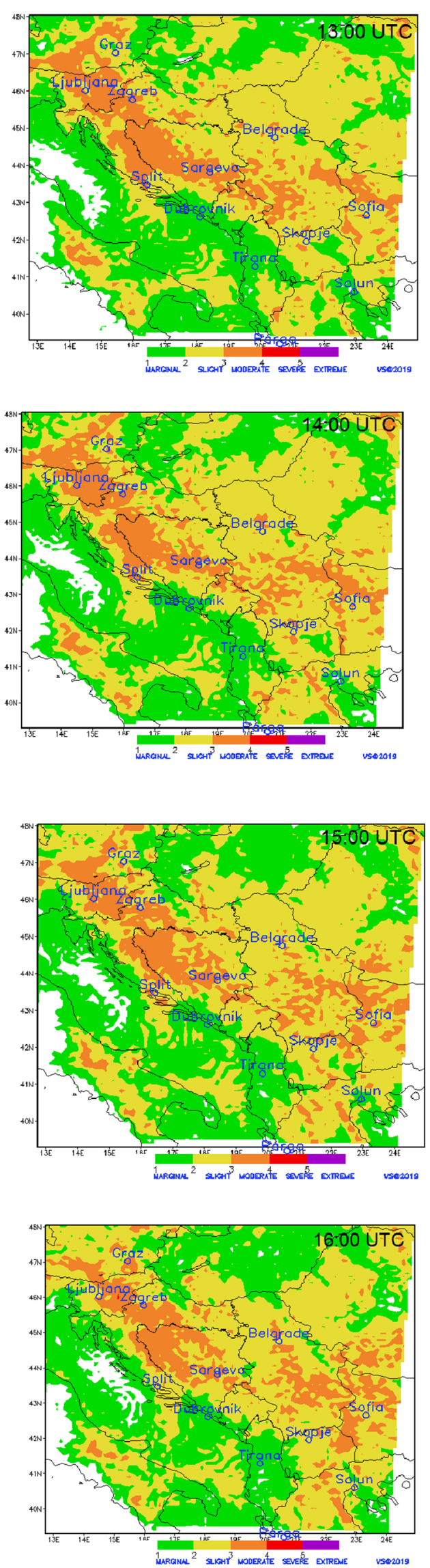
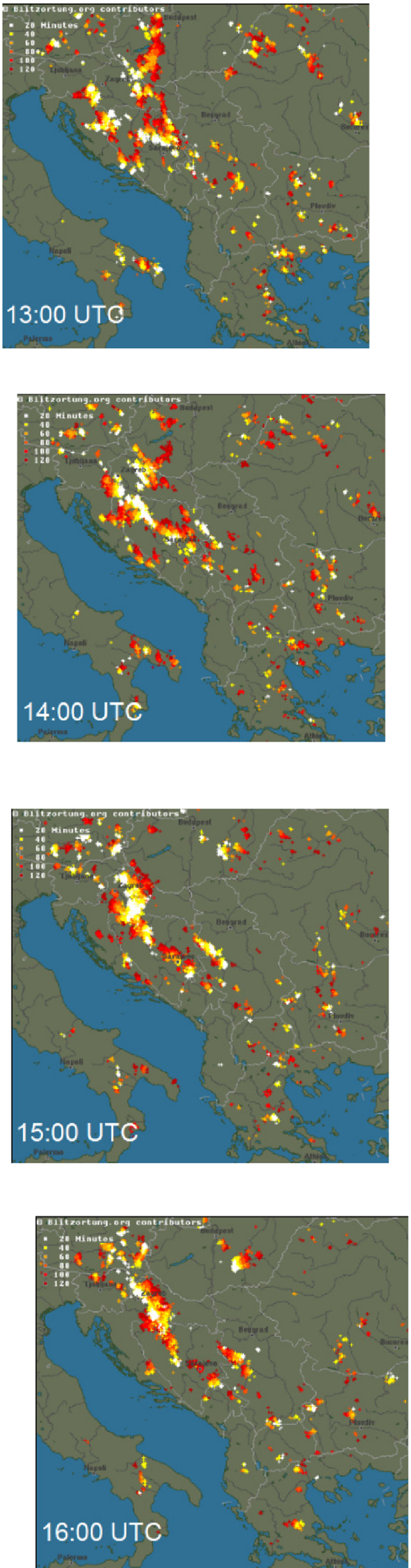
Table 3 Contingency table with scores for southeast Europe - May 1st - October 1st, 2019

\begin{tabular}{|c|c|c|c|c|c|c|c|c|c|c|c|c|c|c|c|}
\hline SCORES & VIE & VEN & LJU & BUD & ZAG & SAR & BEL & $\mathrm{SOF}$ & SKP & THES & PODG & BARI & ROMA & BUCH & DUB \\
\hline $\mathrm{a}$ & 12 & 14 & 9 & 3 & 12 & 7 & 4 & 7 & 5 & 4 & 7 & 7 & 5 & 4 & 7 \\
\hline $\mathrm{b}$ & 2 & 4 & 2 & 2 & 4 & 2 & 2 & 2 & 2 & 2 & 2 & 2 & 3 & 2 & 2 \\
\hline $\mathrm{c}$ & 2 & 1 & 1 & 1 & 1 & 2 & 2 & 1 & 1 & 1 & 1 & 1 & 1 & 1 & 1 \\
\hline d & 38 & 35 & 42 & 48 & 37 & 43 & 45 & 44 & 45 & 47 & 44 & 44 & 44 & 47 & 44 \\
\hline$a+b+c+d$ & 54 & 54 & 54 & 54 & 54 & 54 & 54 & 54 & 54 & 54 & 54 & 54 & 54 & 54 & 54 \\
\hline$a+c$ & 14 & 15 & 10 & 4 & 13 & 9 & 6 & 8 & 6 & 5 & 8 & 8 & 6 & 5 & 8 \\
\hline$b+d$ & 40 & 39 & 43 & 50 & 41 & 45 & 47 & 46 & 47 & 49 & 46 & 46 & 47 & 49 & 46 \\
\hline$a+d$ & 50 & 49 & 49 & 51 & 49 & 50 & 49 & 51 & 49 & 51 & 51 & 51 & 49 & 51 & 51 \\
\hline$c+d$ & 40 & 36 & 43 & 49 & 38 & 45 & 47 & 45 & 45 & 48 & 45 & 48 & 45 & 48 & 45 \\
\hline$a+b$ & 14 & 18 & 11 & 5 & 16 & 9 & 6 & 9 & 7 & 6 & 9 & 9 & 8 & 6 & 9 \\
\hline$a+b+c$ & 16 & 19 & 12 & 6 & 17 & 11 & 8 & 10 & 8 & 7 & 10 & 10 & 10 & 7 & 10 \\
\hline$a_{r}=(a+b)(a+c) / T$ & 3,63 & 5,00 & 2,04 & 0,37 & 3,85 & 1,50 & 0,67 & 1,33 & 0,78 & 0,56 & 1,33 & 1,33 & 0,89 & 0,56 & 1,33 \\
\hline$b_{r}=\left(a+b+c-a_{r}\right)$ & 12,37 & 14,00 & 9,96 & 5,63 & 13,15 & 9,50 & 7,33 & 8,67 & 7,22 & 6,44 & 8,67 & 8,67 & 9,11 & 6,44 & 8,67 \\
\hline $\mathrm{HR}=\mathrm{a} /(\mathrm{a}+\mathrm{c})$ & 0,86 & 0,93 & 0,9 & 0,75 & 0,92 & 0,78 & 0,67 & 0,88 & 0,83 & 0,80 & 0,88 & 0,88 & 0,83 & 0,80 & 0,88 \\
\hline $\mathrm{FAR}=\mathrm{b} /(\mathrm{a}+\mathrm{b})$ & 0,14 & 0,22 & 0,18 & 0,4 & 0,25 & 0,22 & 0,33 & 0,22 & 0,22 & 0,33 & 0,22 & 0,22 & 0,38 & 0,33 & 0,22 \\
\hline BIAS $=(a+b) /(a+c)$ & 1 & 1,2 & 1,1 & 1,25 & 1,23 & 1,00 & 1,00 & 1,13 & 1,16 & 1,20 & 1,13 & 1,13 & 1,33 & 1,20 & 1,13 \\
\hline $\mathrm{CSI}=\mathrm{a} /(\mathrm{a}+\mathrm{b}+\mathrm{c})$ & 0,75 & 0,73 & 0,75 & 0,5 & 0,71 & 0,63 & 0,50 & 0,70 & 0,63 & 0,57 & 0,70 & 0,70 & 0,50 & 0,57 & 0,70 \\
\hline $\mathrm{ETS}=\left(\mathrm{a}-\mathrm{a}_{\mathrm{r}}\right) / \mathrm{b}_{\mathrm{r}}$ & 0,68 & 0,64 & 0,7 & 0,47 & 0,62 & 0,58 & 0,45 & 0,65 & 0,58 & 0,53 & 0,65 & 0,65 & 0,45 & 0,53 & 0,65 \\
\hline HSS & 0,81 & 0,74 & 0,72 & 0,64 & 0,77 & 0,73 & 0,60 & 0,81 & 0,65 & 0,70 & 0,79 & 0,75 & 0,64 & 0,70 & 0,79 \\
\hline $\mathrm{FA}=\mathrm{b} /(\mathrm{b}+\mathrm{d})$ & 0,05 & 0,05 & 0,05 & 0,04 & 0,1 & 0,04 & 0,04 & 0,04 & 0,04 & 0,04 & 0,04 & 0,04 & 0,06 & 0,04 & 0,04 \\
\hline SEDS & 0,79 & 0,79 & 0,81 & 0,72 & 0,75 & 0,75 & 0,68 & 0,81 & 0,79 & 0,93 & 0,81 & 0,81 & 0,73 & 0,75 & 0,81 \\
\hline $\mathrm{KSS}=\mathrm{HR}-\mathrm{FA}$ & 0,81 & 0,88 & 0,85 & 0,71 & 0,82 & 0,74 & 0,63 & 0,84 & 0,79 & 0,76 & 0,84 & 0,84 & 0,77 & 0,76 & 0,84 \\
\hline
\end{tabular}

\subsection{Verification of the Severe Weather Forecast and Alert}

The scientific verification is an important task which serves as an objective measure of forecast quality. It represents an important and essential ingredient in the forecast process. The main goal here is to evaluate and verify the significance of the Novel Thunderstorm Alert System (NOTHAS) and the level of accuracy, identifying the strengths and weaknesses of the forecast system. More specifically the main need is to demonstrate the skills and performances of NOTHAS and to determine the accuracy of various guidance products for the selected domain. While there are standard verification methods applied for routine forecast evaluation of weather forecast and warning, no single verification measure provides complete information about the quality of the forecast and warning products. The reference scores that are commonly used are limited in the sense that they only measure a specific aspect of the forecast quality. Thus it is preferable to use more complementary scores which will significantly increase the forecast value and complete the picture of the forecast accuracy. In this context, the present verification follows the guideline of the World Meteorological Organization verification procedure implemented into Severe Weather Forecasting
Demonstration Project (SWFDP). ${ }^{2}$ The following procedure has been applied to verify the severe weather forecast and Alert tool NOTHAS:

1. Selection of the model forecast domain that covers Southeastern Europe;

2. Definition of subregions (countries) and the main cities located in the centre of these (climatologically homogeneous) subdomains;

3. Provision of the representative observational data for verification;

4. The domain locations and sizes should be consistent with affective potential impacts.

The next task is the preparation of the contingency table (Table 3) with a matched set of forecast and observations which is not a simple matter. The observational data set for our verification purposes are taken from Europe Severe Weather Database (ESWD), ${ }^{3}$ the interactive weather forecasting services worldwide (Windy.com) as well as lightning data

\footnotetext{
${ }^{2}$ More details about SWDP could be found on the following link: (https:// www.wmo.int/pages/prog/www/swfdp/).

${ }^{3}$ For more information reader is invited to visit the following web site: https:// www.eswd.eu
} 

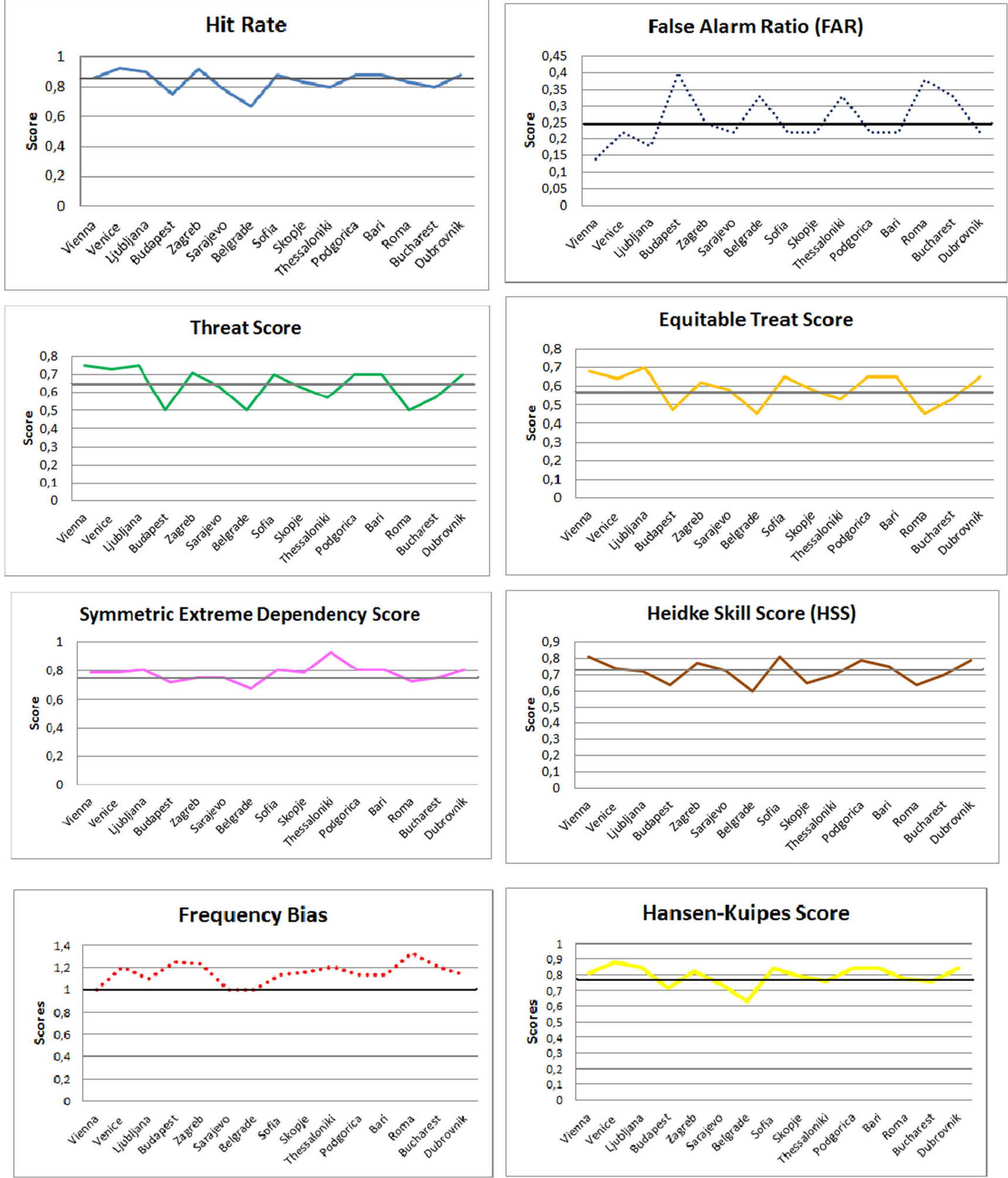

Fig. 8 Verification scores for NOTHAS severe weather forecast and Alert for South-East-Europe domain for $24 \mathrm{~h}$ during mid-latitude convective season (May-October 2019). The solid straight line in each distribution represents the averaged rate 


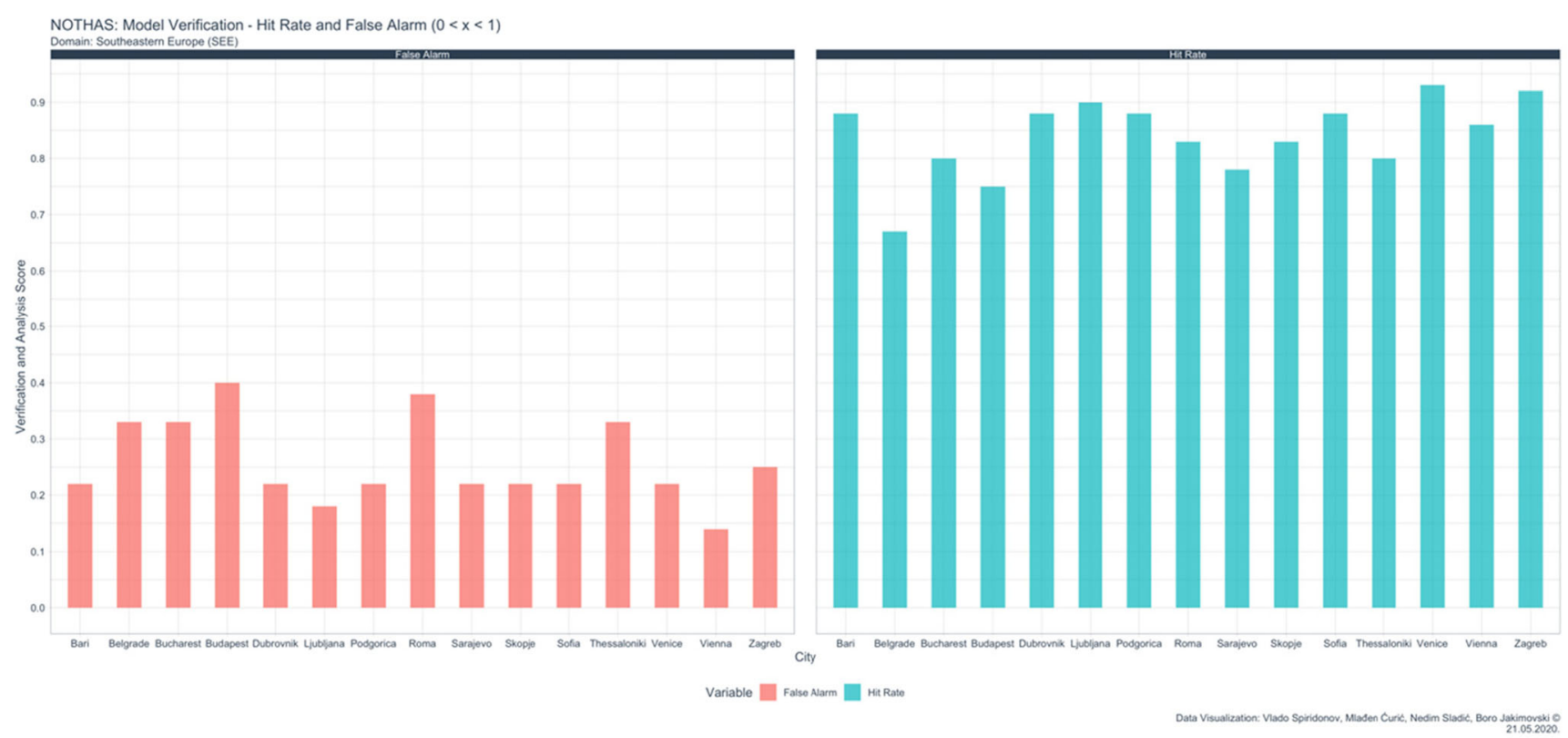

Fig. 9 Same as Fig. 8, but for Hit Rate and False Alert Ratio distribution for all evaluated sub-regions

provided by (Blitzortung.org). ${ }^{4}$ The verified period taken dates from May 1st, 2019, through to October 1st, 2019, including some historic very severe weather cases. The observational data are carefully evaluated case by case using the comprehensive ESWD archive by defining the following severe weather elements: heavy rain, large hail, tornado, and severe wind gust. In addition, the spatial distribution of lightning is evaluated together with radar reflectivity patterns. For NOTHAS, the forecast event is the expected occurrence of severe weather conditions somewhere in the forecast subdomains (in our case fifteen selected countries), sometime during the valid area and period of the forecast and warning. It should be pointed out that in the verification process, categorical levels are taken (in particular, 3 to 5), which indicate the occurrence of an enhanced, severe and extreme weather. Furthermore, it is considered that the size and the signature of the patterns which indicate the type of the case (e.g. single case-isolated case, widespread affected area or other specific forms). Four significant elements are defined in the verification process:

- A "hit" denoted by (a) is defined by the occurrence of at least one observation in the sub-domain, anytime during the forecast period;

- A "false Alert" (b) occurs when severe weather is forecasted but there is no severe weather observed;

\footnotetext{
${ }^{4}$ Blitzortung.org provides lightning and thunderstorm information in real time on maps for Europe and other parts of the world.
}

- A "missed event" (c) indicates when severe weather is forecasted outside of the reported area (outside of the subdomain) or severe weather is reported but no alert is issued;

- "A correct non-event" (d) is recorded for each forecast for which no warning is issued and no severe weather is reported.

In the text below, the calculation of scores which are functions of entries are listed in the contingency Table 3 . The short abbreviations of scores (e.g. HR, FAR, BIAS, CSI, ETS, HSS, FA, SEDS and KSS) marked with capital letters represent Hit Rate, False Alert Ratio, Frequency Bias, Threat Score, Heidke Skill Score, False Alert Rate, Hanssen-Kuipers Score and Symmetric extremal dependency score, respectively. The Heidke Skill Score is useful for evaluation if the forecast offers some improvement over the choice of an unskilled standard forecast.

$$
H S S=\frac{(a+d)-\frac{(a+b)(a+c)+(c+d)(b+d)}{T}}{T-\frac{(a+b)(a+c)+(c+d)(b+d)}{T}}
$$

while the Symmetric extreme dependency score is given with the relation

$$
\operatorname{SEDS}=\frac{\left[\log \left(\frac{a+b}{T}\right)-\log \left(\frac{a}{a+c}\right)\right]}{\left[\log \left(\frac{a+c}{T}\right)+\log \left(\frac{a}{a+c}\right)\right]}
$$


Fig. 10 Severe weather forecast and warning on August 6th, 2016.

(a) Europe Storm Forecast

Experiment (ESTOFEX); (b)

Novel Thunderstorm Alert

System (NOTHAS).

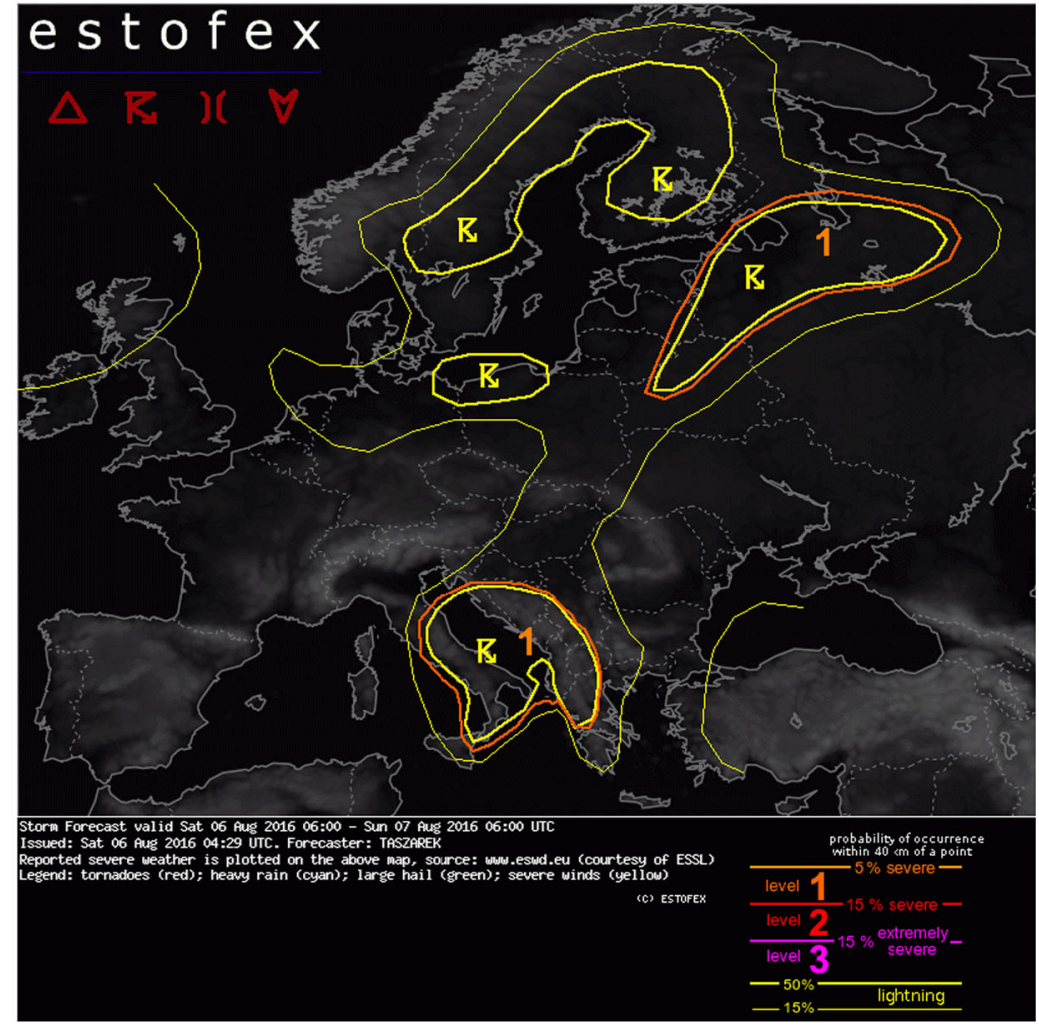

(a)

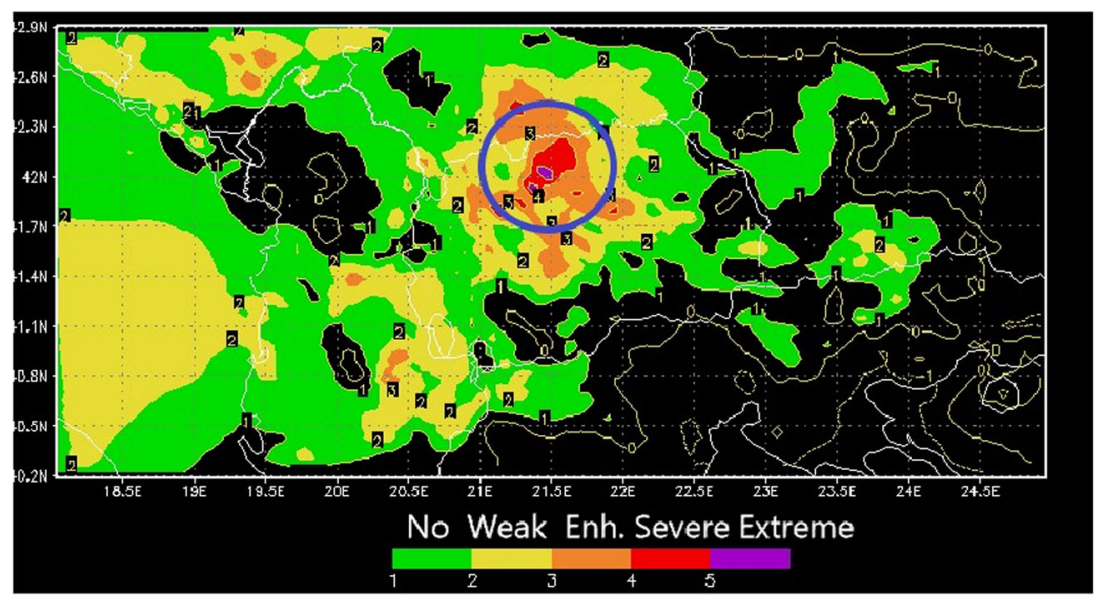

(b)

control the so-called "forecast frequency", the number of times the event is forecasted divided by the total number of the cases in the verification sample. In general, the scores provide the most powerful information if they are computed for a large number of examples. These scores are interpreted in light of the different aspects of forecast and warning quality. The scores are given in Fig. 8 (HR, FAR, TS, ETS and SEDS), and represent a measure of the NOTHAS "accuracy". The
Heat Rate which has a range of 0 to 1 (with 1 representing a perfect warning of severe weather) and its sensitive to miss events has shown an average rate of 0,82 which indicate high accuracy. It is usually suggested that HR be used in conjunction with False Alert Ratio (FAR) or the false Alert rate (FA) (Fig. 9). While the averaged false Alert ratio is about 0,25 , a high accuracy is compensated by Hit Rate, whose weighted calculated rate is about 0,84 . The Threat Score CSI (critical 
success index), which is more complete than HR and FAR as it is sensitive to both missed and false Alert, indicates a quite high average value of 0,65 . The similar rate of about 0,58 is calculated for the Equitable Threat Score (ETS), which adjusts for the effects of differences in the climatological frequencies of the event between samples. The last score, which measures forecast accuracy is Symmetric extreme dependency score SEDS as a new score, is designed specifically for extreme events with higher threshold rates. In our case, it indicates a high averaged rate of about 0,77 while for the extreme events (e.g. Belgrade, June 23rd, 2019; Thessaloniki, July 10th, 2019, and Skopje, August 06th, 2016), it even has a higher rate of about 8,0 . Although data were taken for only one season, the verification showed positive results in terms of the accuracy of the tool for forecasting and warning of severe weather. The average value $(0,7)$ of precision scores implies that NOTHAS successfully predicts small-scale local hazards. The verification results would be even better, because during the verification, we arbitrarily added one case of false Alert and one missed event, to avoid subjectivity in some way, given the small subdomain area representative for convective scale processes. What is important to note is that from all evaluated samples five were extremely severe cases where the NOTHAS showed high accuracy. Here we would like to single out the extreme deadly supercell thunderstorm case that occurred on August 6th, 2016 (see Spiridonov and Ćurić 2019). As shown in Fig. 10, ESTOFEX for this case issued level 1 for the western Balkan Peninsula mainly for large hail, excessive precipitation and severe wind gusts, while missed to predict a high probability for occurrence of extremely severe convective weather over Macedonia. A similar assessment for potentially dangerous weather over target area was issued by Meteoalarm (https://www.meteoalarm.eu/), as web platform of the Network of European Meteorological Services (EUMETNET) (not shown). NOTHAS showed a distinct accuracy in the spatial and temporal forecast and warning, anticipating the maximum category level 5 . The thunderstorm outlook shown in Fig. 10 very clearly indicated a high potential for occurrence of very severe (red shaded pattern) and even extremely severe convective weather (pink shaded pattern), over small urban and rural area of Skopje city.

\section{Discussion and Conclusions}

The present research paper aims to introduce the idea of the development of "A Novel Thunderstorm Alert System" (NOTHAS). The system has been extensively tested for forecast and warnings of mid-latitude and tropical convective events. It is a novel thunderstorm alert system based on the guidance of state-of-the-art ensemble WRF-ARW model forecast and a suite of postprocessing tool for quantitative assessment of thunderstorm severity and risk categories. A novel diagnostic algorithm utilizes a multivariate Weibull probability density distribution function which comprises several potential convective instability and physical parameters to calculate the forecast probability based on the individual contribution of variables. The calculations are provided in model output time over the selected domain which covers Southeastern Europe. NOTHAS provides graphical outputs on an hourly basis which depict non-severe thunderstorm areas and severe thunderstorm threats across the selected model domain, along with a mesoscale discussion and a text narrative report 1-3 days ahead. Subjective verification during the whole season (April-September 2019) over 183-days period demonstrates a good potential and considerable skill in the detection of a different type of storms and convective modes across South-eastern Europe (SEE). The lightning patterns with intense convective activities are well captured $24 \mathrm{~h}$ in advance, with the spatiotemporal alignment of highlighting patterns where severe convection is anticipated. In a few severe weather convective cases, NOTHAS showed exceptional performance with remarkably accurate assessment of thunderstorm treats and category level " 5 " as the potential for the occurrence of extremely severe weather. A typical example is the Halkidiki supercell storm on July 10th, 2019, when the system accurately anticipated the location of extremely severe weather $24 \mathrm{~h}$ in advance. Moreover, NOTHAS was also successful in advanced prediction $(72 \mathrm{~h})$ of the tropical cyclone "Dorian", the tropical storm "Pabuk" and many other individual thunderstorm cases over South-eastern Europe (SEE) and other regions including Paraguay, Canada, and Thailand. Since this is a preliminary work, the conclusions should be drawn with caution, as additional work is required for testing and verifying the system performance on different geographical scales and atmospheric systems.

Acknowledgements The authors thank the participants and the many collaborators who contributed generously and whose work significantly ensured the success of the numerical experiments for 2019. The authors are very grateful to Prof. Dr. Anastazija Kirkova-Naskova for proofreading the article. A particular thanks goes to Mr. Igor Kovacic for his continuous evaluation and useful remarks regarding the results and the system performances. We are most grateful to Dr. Julian Baez Benitez for the collaborative work in implementing and testing the NOTHAS system at the Technical Catholic University in Asuncion, Paraguay, during 2019/2020. We would also like to thank the Faculty of Computer Science and Engineering (FINKI) at "Ss. Cyril and Methodius University, Skopje", and the team from "Inteligenta" led by Prof. Goran Velinov for their support and utilizing their computing centre and other facilities. Finally, the authors express their deep gratitude to Prof. Dr. Eun-Soon IM (editor of APJAS) for her efforts and endeavours during the reviewing process and to the anonymous reviewers for their useful and constructive recommendations.

Funding Information Open access funding provided by University of Vienna. 


\section{Appendix}

\section{Total Totals Index (TT)}

The Total Totals Index (TT) includes two important elements: the static stability and the moisture (dewpoint). It is also included in the calculation of Severe Weather Threat Index (SWEAT). Thus, for TT we obtain

$T T=V T+C T=T(850 m b)-T(500 m b)+T_{d}(850 m b)-T(500 m b)$

In case when $T T=55$ to 60 , severe thunderstorms are possible.

\section{K-Index}

$\mathrm{K}$-index represents a measure of a thunderstorm potential which depends on conditional instability, i.e. the vertical distribution of temperature (lapse rate), and low-level moisture content into the atmosphere. $\mathrm{K}$-index is given by the following relation

$\mathrm{K}=\mathrm{T}(850 \mathrm{mb})+T_{d}(850 \mathrm{mb})-\mathrm{T}(500 \mathrm{mb})-\mathrm{DD}(700 \mathrm{mb})$

where $\mathrm{T}$ is the temperature, $T_{d}$ represents dewpoint temperature and DD is a dewpoint depression at a given level.

When $K=40$, there is a high probability for thunderstorms with heavy rain.

\section{Lifted Index (LI)}

Lifted Index is a useful measure of atmospheric stability which calculates the difference between a lifted parcel temperature at $500 \mathrm{mb}$ and the environmental temperature at the same pressure level.

$L I=T_{e}(500 m b)-T_{p}(500)$

A positive index means that a parcel of air, if lifted, would be colder than the surrounding air at $500 \mathrm{mb}$. The air is, therefore, stable and would resist vertical motion. A negative index means that the low-level air, if lifted to $500 \mathrm{mb}$, would be warmer than the surrounding air. The air is unstable and indicates the possibility of convection.

$L I<-9\left({ }^{\circ} C\right)$ The air is extremely unstable.

\section{Severe Weather Threat Index (SWEAT)}

SWEAT is a very useful potential instability convective index as it incorporates several parameters into one index including (low-level; moisture ( $850 \mathrm{mb}$ dew point), instability (Total Totals Index), lower and middle-level $(850 \mathrm{mb}$ and $500 \mathrm{mb}$ ) wind speeds, and warm air advection (i.e. wind veering between this layer).
$S W E A T=12\left[T_{d}(850)\right]+20(T T-49)+2+(f 8)+f 5+125(S+0.2)$

where TT is the Total Totals Index, $\mathrm{f} 8$ and $\mathrm{f5}$ represent the $850 \mathrm{mb}$ and $500 \mathrm{mb}$ wind speed in knots or $(1 \mathrm{knot}=$ $0.514444 \mathrm{~m} / \mathrm{s})$, respectively, and $S=\sin \left(500 \mathrm{mb} b_{\text {dir }}-850 \mathrm{mb}\right.$ $d_{\text {dir }}$ ), i.e. the sine of the angle between the $500 \mathrm{mb}$ wind directions (the shear term).

SWEAT $>400$ There is a potential for tornadoes.

\section{Convective Available Potential Energy (CAPE)}

CAPE represents the maximum amount of potential energy that the air parcel has available for convection or CAPE calculates the amount of the buoyant energy available to accelerate a parcel vertically from the Level of Free Convection (LFC) where pressure is $p_{f}$ to the Equilibrium Level (EL) denoted by $p_{n}$. It is derived from a parcel theory that assumes the following conditions:

a) A rising air parcel exhibits no environmental entrainment;

b) the parcel rises moist adiabatically;

c) all precipitation falls out of the parcel (no water loading);

d) the parcel pressure is equal to the environmental pressure.

$C A P E=\int_{p_{f}}^{p_{n}} R_{d}\left(T_{v p}-T_{v e}\right) d \ln p$

$C A P E>3500$ to 4000 The air parcel is extremely unstable.

\section{Bulk Richardson Number (BRN)}

The BRN is an index of the buoyancy energy expressed through CAPE to the vertical wind shear of the environment.

$B R N=\frac{\left(g / T_{v}\right) \Delta \theta_{v} \Delta z}{\left(\Delta u^{2}\right)+\left(\Delta v^{2}\right)}$

where $T_{v}$ is absolute virtual temperature, $\Delta \theta_{v}$ is virtual potential temperature difference across a layer of thickness $\Delta z$, and $\Delta u$ and $\Delta v$ are the changes in horizontal wind components across that same layer.

$B R N=10$ to 45 It is associated with supercell development.

\section{Storm Relative Helicity (SRH)}

Strom Relative Helicity is an estimate measure of thunderstorm potential to develop a rotating updraft and mesocyclone. $\mathrm{SRH}$ includes an environment vertical wind shear and horizontal vorticity

$S R H=-\int_{0}^{h}\left[(\vec{V}-\vec{C}) \cdot \vec{k} x\left(\frac{\partial V}{\partial z}\right)\right] d z$ 
where vector $\vec{V}$ is the environmental wind vector, $\vec{C}$ is the storm's motion (translation) velocity $\vec{k} x\left(\frac{\partial V}{\partial z}\right)$ is the horizontal vorticity, and vector $\vec{k}$ is the unit vector in the vertical. SRH is calculated for the lowest $1-\mathrm{km}$ and $3-\mathrm{km}$ layers above ground level.

$S R H=150$ represents the approximate threshold for supercell development.

$S R H=150$ to 300 weak tornadoes (F0 and F1) are possible.

Physical parameters:

\section{Radar reflectivity (REFD)}

Radar reflectivity (REFD) is substantial physical parameter as it indicates the thunderstorm structural and evolutionary properties and storm intensity. REFD is derived surface radar reflectivity (dBZ). This is the output from the reflectivity algorithm at the lowest model level provided on hourly basis at the model output time.

$R E F D>60 \mathrm{dBZ}$ Very severe thunderstorms are possible.

\section{Brightness Temperature (BRTH)}

(BRTH) is a measure of thunderstorm intensity and development of overshooting tops. Model fields include vertical profiles of temperatures, water vapour mixing ratio, hydrometeor mixing ratios predicted by Thomson's microphysics scheme along with surface skin temperature and 10-m wind speed (see Han et al. 2006).

$B R T H<-60^{\circ} \mathrm{C}$ Deep convective clouds with overshooting tops; Severe thunderstorms possible

\section{A total accumulated precipitation (RAINT)}

Total Accumulation of Precipitation is an important physical parameter about the total accumulated precipitation from the convection and microphysics scheme (mm) is given.

RAINT $=($ RAINS + RAINNC $)$

This is the accumulation of convective precipitation and microphysical scheme over one-hour simulation.

RAINT $>30 \mathrm{~mm}$ Severe thunderstorms possible with heavy rainfall potential.

Open Access This article is licensed under a Creative Commons Attribution 4.0 International License, which permits use, sharing, adaptation, distribution and reproduction in any medium or format, as long as you give appropriate credit to the original author(s) and the source, provide a link to the Creative Commons licence, and indicate if changes were made. The images or other third party material in this article are included in the article's Creative Commons licence, unless indicated otherwise in a credit line to the material. If material is not included in the article's Creative Commons licence and your intended use is not permitted by statutory regulation or exceeds the permitted use, you will need to obtain permission directly from the copyright holder. To view a copy of this licence, visit http://creativecommons.org/licenses/by/4.0/.

\section{References}

Blanchard, D.O.: Assessing the vertical distribution of convective available potential energy. Wea. Forecasting. 13, 870-877 (1998)

Browning, K.A.: Cellular structure of convective storms. Meteorol. Mag. 91(1085), 341-350 (1962)

Browning, K.A.: Airflow and precipitation trajectories within severe local storms which travel to the right of the mean wind. J. Atmos. Sci. 21, 634-639 (1964)

Clark, A.J., Coauthors: An overview of the 2010 Hazardous Weather Testbed experimental forecast program spring experiment. Bull. Amer. Meteor. Soc. 93, 55-74 (2012). https://doi.org/10.1175/ BAMS-D-11-00040.1

Ćurić, M., Janc, D., Vučković, V.: The influence of merging and individual storm splitting on mesoscale convective system formation. Atmos. Res. 93, 21-29 (2009)

Ćurić, M., Janc, D.: Differential heating influence on hailstorm vortex pair evolution. Q. J. R. Meteorol. Soc. 138, 72-80 (2012)

Dahl, J.M.L., Hoeller, H., Schumann, U.: Modeling the flash rate of thunderstorms. Part I: Framework. Mon. Wea. Rev. 139, 3093 3111 (2011a)

Dahl, J.M.L., Hoeller, H., Schumann, U.: Modeling the flash rate of thunderstorms. Part II: Implementation. Mon. Wea. Rev. 139, 3112-3124 (2011b)

Davies-Jones, R.P.: Streamwise vorticity: the origin of updraft rotation in supercell storms. J. Atmos. Sci. 41, 2991-3006 (1984)

Dotzek, N., Groenemeijer, P., Feuerstein, B., Holzer, A.M.: Overview of ESSL's severe convective storms research using the European severe weather database ESWD. Atmos. Res. 93, 575-586 (2009)

Doswell III, C.A., Brooks, H.E., Maddox, R.A.: Flash flood forecasting: an ingredients-based methodology. Wea. Forecasting. 11, 560-581 (1996)

Doswell III, C.A., Schultz, D.M.: On the use of indices and parameters in forecasting severe storms. Electronic J. Severe Storms Meteor. 1(3), $1-22(2006)$

Doswell III, C.A., Rasmussen, E.N.: The effect of neglecting the virtual temperature correction on CAPE calculations. Wea. Forecasting. 9, 625-629 (1994)

Gallo, B.T., Clark, A.J., Dembek, S.R.: Forecasting tornadoes using convection-permitting ensembles. Wea. Forecasting. 31, 273-295 (2016)

Eckel, F.A., Mass, C.F.: Effective mesoscale, short-range ensemble forecasting. Weather Forecast. 20, 3238-3350 (2005)

Gallo, B.T., coauthors: Breaking new ground in severe weather prediction: the $2015 \mathrm{NOAA} /$ hazardous weather Testbed spring forecasting experiment. Wea. Forecasting. 32, 1541-1568 (2017). https:// doi.org/10.1175/WAF-D-16-0178.1

Gallo, B.T., Kalb, C.P., Gotway, J.H., Fisher, H.H., Roberts, B., Jirak, I.L., Clark, A.J., Alexander, C., Jensen, T.L.: Initial development and testing of a convection-allowing model scorecard. Bull. Amer. Meteor. Soc. 100(12), 367-384 (2019)

Han, J., Wang, W., Kwon, Y. C., Hong, S.-Y., Tallapragada, V., \& Yang, F.: Updates in the NCEP GFS cumulus convection schemes with scale and aerosol awareness. Weather and Forecasting, 32(5), 20052017 (2017). https://doi.org/10.1175/WAF-D-17-0046.1

Hart, J.A., Cohen, A.E.: The statistical severe convective risk assessment model. Wea. Forecasting. 31, 1697-1714 (2016). https://doi.org/10. 1175/WAF-D-16-0004.1 
Haklander, A.J., van Delden, A.: Thunderstorm predictors and their forecast skill for the Netherlands. Atmos. Res. 67-68, 273-299 (2003)

Schultz, C.J., Petersen, W.A., and Carey, L.D.: Lightning and severe weather: A comparison between total and cloud-to-ground lightning trends. Wea. Forecasting, 26, 744-755 (2011). https://doi.org/10. 1175/WAF-D-10-05026.1

Shin, H.H., and Hong S.Y.: Intercomparison of planetary boundary-layer parameterizations in the WRF model for a single day from CASES99, Boundary Layer Meteorol., 139, 261- 281 (2011). https://doi. org/10.1007/s10546-010-9583-z

Skamarock, W. C., Klemp, J. B., Dudhia, J., Gill, D. O., Barker, D. M., Wang, W., \& Powers, J. G. A Description of the Advanced Research WRF Version 2 (No. NCAR/TN-468+STR). University Corporation for Atmospheric Research (2005) https://doi.org/10. 5065/D6DZ069T

Skamarock, W.C., Klemp, J.B., Dudhia, J., Gill, D.O., Barker, D., Duda, M.G.: ... Powers, J. G. a description of the advanced research WRF version 3 (no. NCAR/TN-475+STR). University Corporation for Atmospheric Research (2008)

Skamarock, W.C., Klemp, J.B., Dudhia, J., Gill, D.O., Barker, D., Duda, M.G.: ... Powers, J. G. a description of the advanced research WRF version 3 (no. NCAR/TN-475+STR). University Corporation for Atmospheric Research (2008) Schultz, C. J., Petersen, W. a., and Carey, L. D.: lightning and severe weather: a comparison between total and cloud-to-ground lightning trends. Wea. Forecasting. 26, 744-755 (2011). https://doi.org/10.1175/WAF-D-10-05026.1

Stensrud, D.J., Coauthors: Convective-scale warn-on-forecast system: A vision for 2020. Bull. Amer. Meteor. Soc. 90, 1487-1500 (2009). https://doi.org/10.1175/2009BAMS2795.1

Stensrud, D.J., Bao, J.-W., Warner, T.T.: Using initial condition and model physics perturbations in short-range ensemble simulations of mesoscale convective systems. Mon Wea Rev. 128, 2077-2107 (2000)

Spiridonov, V., Dimitrovski, Z., Ćurić, M.: A three-dimensional simulation of supercell convective storm. Adv. Meteorol. 2010 (15), 1-15 (2010)

Spiridonov, V., Curic, M.: A storm modeling system as an advanced tool in prediction of well organized slowly moving convective cloud system and early warning of severe weather risk. Asia-Pacific J Atmos Sci. 51, 61-75 (2015). https://doi.org/10.1007/s13143-0140060-3

Spiridonov, V., Ćurić, M.: Evaluation of Supercell storm triggering factors based on a cloud resolving model simulation. Asia-Pac. J. Atmos. Sci. 55, 439-458 (2019). https://doi.org/10.1007/s13143018-0070-7

Thompson, R.L., Mead, C.M., Edwards, R.: Effective storm-relative helicity and bulk shear in supercell thunderstorm environments. Wea. Forecasting. 22, 102-115 (2003)
Thompson, R.L., Smith, B.T., Grams, J.S., Dean, A.R., Broyles, C.: Convective modes for significant severe thunderstorms in the contiguous United States. Part II: Supercell and QLCS tornado environments. Wea. Forecasting. 27, 1136-1154 (2012). https://doi.org/10. 1175/WAF-D-11-00116.1

Thompson, G., Field, P.R., Rasmussen, R.M., Hall, W.D.: Explicit forecasts of winter precipitation using an improved bulk microphysics scheme. Part II: Implementation of a new snow parameterization. Mon.Wea. Rev. 136, 5095-5115 (2008)

Thompson, G., Eidhammer, T.: A Study of Aerosol Impacts on Clouds and Precipitation Development in a Large Winter Cyclone, J. Atmos. Sci. (2014). https://doi.org/10.1175/JAS-D-13-0305.1

Tuschy, H.: Examination of severe thunderstorm outbreaks in Central Europe m.Sc. Thesis. Institute of Meteorology and Geophysics, University of Innsbruck, https://www.uibk.ac.at/acinn/theses/

Warner, T.: Numerical Weather and Climate Prediction. Cambridge University Press, Cambridge (2011)

Weisman, M.L.: On the use of vertical wind shear versus helicity in interpreting supercell dynamics. Preprints, 18th Conf. on Severe Local Storms, San Francisco, CA, Amer. Meteor. Soc. 200-204 (1996).

Weisman, M. L., C.Davis, W.Wang, K. W.Manning, and J. B.Klemp: Experiences with 0-36-h explicit convective forecasts with the WRF-ARW model. Wea. Forecasting. 23, 407-437 (2008).

Weisman, M.L., Rotunno, R.: The use of vertical wind shear versus helicity in interpreting supercell dynamics. J. Atmos. Sci. 57, 1452-1472 (2000). https://doi.org/10.1175/1520-0469(2000) 057<1452:TUOVWS $>2.0 . \mathrm{CO} ; 2$

Weisman, M.L., Klemp, J.B.: The dependence of numerically simulated convective storms on vertical wind shear and buoyancy. Mon. Wea. Rev. 110, 504-520 (1982)

Xue, M., Kong, F., Thomas, K.W., Gao, J., Wang, Y., Brewster, K., Droegemeier, K.K., Kain, J., Weiss, S., Bright, D., Coniglio, M., and $\mathrm{Du}$, J.: CAPS realtime storm-scale ensemble and highresolution forecasts as part of the NOAA Hazardous Weather Testbed 2008 Spring Experiment. 24th Conf. Several Local Storms, Savannah, GA, Ameri.Meteor. Soc., Paper 12.2 (2008)

Xue, M., Wang, D.-H., Gao, J.-D., Brewster, K., Droegemeier, K.K.: The advanced regional prediction system (ARPS), storm-scale numerical weather prediction and data assimilation. Meteor. Atmos. Phys. 82, 139-170 (2003). https://doi.org/10.1007/s00703-001-0595-6

Publisher's Note Springer Nature remains neutral with regard to jurisdictional claims in published maps and institutional affiliations. 